\title{
Ülkelerin İnsani Gelişmişlik Sınıflamalarının UTADIS Yaklaşımı Aracılığıyla Yeniden Hesaplanması ve Değerlendirilmesi ${ }^{12}$
}

\section{Kübra AKYOL ÖZCAN ${ }^{3}$ Erkan OKTAY ${ }^{4}$}

\begin{tabular}{|c|c|}
\hline $\begin{array}{c}\text { Kabul Tarihi/ Accepted } \\
06 / 07 / 2020\end{array}$ & $\begin{array}{c}\text { Yayın Tarihi/ Published } \\
15 / 07 / 2020 \\
\end{array}$ \\
\hline $\begin{array}{l}\text { Citation/Atıf: Akyol Özcan, K. ve Oktay E., (2020), } \\
\text { Sinıflamalarının UTADIS Yaklassımı Aracllığlyla Yeniden Hesap } \\
\text { Atatürk Üniversitesi Iktisadi ve Idari Bilimler Dergisi, } \\
\text { 10.16951/atauniiibd.740505 }\end{array}$ & $\begin{array}{l}\text { kelerin Insani Gelişmişlik } \\
\text { nmast ve Değerlendirilmesi, } \\
34(3): \text { 1153-1180, DOI: }\end{array}$ \\
\hline
\end{tabular}

Öz: Ülkelerin gelişmişlik düzeyini tek başına milli gelirdeki artışla açıklamanın mümkün olmadığını ileri süren Amartya Sen tarafından geliştirilen İnsani Gelişmişlik İndeksi, hesaplamaya sağlık, eğitim ve gelir bileşenlerini de dahil etmektedir. Birleşmiş Milletler Kalkınma Programı (UNDP) tarafından ilk kez 1990 yılında hazırlanan İnsani Gelişmişlik Raporları ile sunulmaya başlanan ülkelerin İnsani Gelişmişlik İndeksi değerleri; Doğumda Yaşam Beklentisi”, "Beklenen Okullaşma Yılı”, “Ortalama Okullaşma Yılı” ve "Kişi Başına Düşen Gayri Safi Milli Gelir” olmak üzere dört kriter kullanılarak ölçülmektedir.

Çalışmada, ülkeleri gelişmişlik düzeylerine göre sınıflandırmak için yukarıda belirtilen dört kritere dayalı ve 188 alternatiften oluşan bir model sunulmuştur. UTADIS tekniği sıralı sınıflandırma problemlerinde başarılı bir şekilde kullanıldığı için ülkelerin doğru gruplamasının bu teknikle tespit edilmesi hedeflenmiştir. Çalışma literatürde az bir uygulama alanına sahip UTADIS tekniğinin ülkelerin İnsani Gelişmişlik İndeksi değerlerine uygulanması açısından bir ilki temsil etmektedir. Uygulanan UTADIS modeli ile 188 alternatifin 111'i UNDP'nin yaptığı gruplama ile aynı sınıflandırılırken, 77'si farklı bir grupta sınıflandırılmıştır. UTADIS analizi sonuçlarına göre birçok ülkenin sınıflandırmasının güncellenmesi gerektiği gözlemlenmiştir.

Anahtar Kelimeler: İnsani Gelişmişlik İndeksi, Çok Kriterli Karar Verme, UTADIS

\section{Recalculation and Evaluation of Human Development Classifciation of Countries via UTADIS} Approach

Abstract: Developed by Amartya Sen who is asserting that countries' level of development cannot be explained with only increase in national income, The Human Development Index incorporates components of health, education and income in calculation. Human Development Index values of countries, first presented with Development Reports prepared by United Nations

${ }^{1}$ Bu çalışma "Ülkelerin insani gelişmişlik sınıflamalarının UTADIS ve sıralı lojistik regresyon modelleri aracılı̆̆lyla yeniden hesaplanması ve değerlendirilmesi" isimli doktora tezinden türetilmiştir.

${ }^{2}$ SDK-2018-6614 nolu BAP projesi ile Atatürk Üniversitesi tarafindan desteklenmiştir.

${ }^{3}$ Arş. Gör. Dr., Bayburt Üniversitesi, Iktisadi ve İdari Bilimler Fakültesi, https://orcid.org/00000002-1158-7017

${ }^{4}$ Prof. Dr., Atatürk Üniversitesi, Iktisadi ve İdari Bilimler Fakültesi, https://orcid.org/0000-0002$\underline{1739-3184}$ 
Ülkelerin İnsani Gelişsmişlik Sinıflamalarının UTADIS Yaklaşımı Aracılı̆̆ıyla Yeniden Hesaplanması ve Değerlendirilmesi

Development Program (UNDP) in the year 1990, are measured using four criteria: "Life Expectancy at Birth", "Expected Years of Schooling", "Mean Years of Schooling" and "Gross national income per capita"

In this study, in order to classify countries according to their level of development a model based on above-mentioned four criteria and consisting of 188 alternatives is presented. Since the UTADIS technique is successfully used in sequential classification problems, it is aimed to determine the correct grouping of countries with this technique. This study represents a first attempt in terms of applying UTADIS technique, which has a limited application in literature, for Human Development Index values of the countries. With the applied UTADIS model, 111 of the 188 alternatives are classified as the same grouping by UNDP, while 77 are classified in a different group. According to the results of UTADIS analysis, observed that the classification of many countries has to be updated.

Keywords: The Human Development Index, Multi Criteria Decision Making, UTADIS

\section{EXTENDED SUMMARY}

Reserarch Problem: The Human Development Reports (HDR), published by UNDP, demonstrate the development level of the countries contained in its content. Validity of the report is accepted on an international platform. These reports, the first published regularly every year, in 1990, provide comprehensive statistics on all countries. The aim of this study is to reclassify 188 countries according to HDI values with UTADIS technique, which is one of the MultiCriterion Decision Making methods (MCDM).

Research Questions: It will be determined whether the 188 countries in the HDRs prepared by UNDP are sorted correctly according to the HDI values and whether the countries are in the correct group.

Literature Review: The UTADIS technique, first produced by Devaud, Groussaud, Jacquet-Lagreze (1980) and developed by Jacquet - Lagreze and Siskos (1982) and Jacquet - Lagreze (1995) and used to create additional benefit functions in sorting problems, is successfully used in sequential classification problems. This study represents a first in terms of the application of the UTADIS technique, which has a small field of practice in the literature, to the HDI values of the countries. Countries have been reclassified according to the HDI, an internationally recognized measure of the level of development. Thus, this study will be a reference to many researchers who investigate the development of countries.

Methodology: This study was applied on 188 countries published by UNDP. UNDP divides countries into four groups based on "Very High", "High", "Medium" and "Low" development value to evaluate countries. Therefore, countries are classified in 4 groups according to index value. There are 51 countries in the first group, 55 in the second group, 41 in the third group and 41 in the fourth group. Countries are grouped by UNDP according to index values and four criteria. These criteria are Life Expectancy at Birth $\left(g_{1}\right)$, Expected Schooling Year $\left(g_{2}\right)$, Mean years of schooling $\left(g_{3}\right)$, and GDP Per Capita $\left(g_{4}\right)$ sorted into. In this study, a model based on four criteria was presented to classify countries according to their levels of development. Alternatives of this model are 188 countries. According to the four criteria and HDI values, the right groups of 
countries were tried to be reidentified with the UTADIS approach. The hypothesis of the study is whether the ranking of 188 countries included in the HDRs prepared by UNDP is the same with the UTADIS model according to the HDIvalues and whether the countries are included in the group made by UNDP. The study used data from 188 countries in the 2016 Report on Human Development published by UNDP in 2017.

Findigs: According to the grouping process made by UNDP; In the first group, in the category of country with very high level of development $C_{1}(51)$, in the second group, in the category of country with high level of development $\left(C_{2}\right)$ 55 , in the third group, in the category of country with medium level of development $\left(C_{3}\right) 41$, and in the fourth group, in the category of country with low level of development $\left(C_{4}\right) 41$ there are countries.

As a result of the UTADIS analysis, countries have been reclassified according to benefit scores in terms of levels of development. 84 of the 188 countries were in the category of countries with a very high $\left(C_{1}\right), 47$ high $\left(C_{2}\right), 30$ in the middle $\left(C_{3}\right)$ and 27 with low $\left(C_{4}\right)$ level of development. UNDP equally accepts the weight of all criteria that make up the HDI. In fact, in real life, this equality is out of the question. The change of weights also changes the classes of countries. The UTADIS method allows this change. As a result, we recommend that the criteria be evaluated independently and that the UTADIS method, one of the sequential classification methods of the MCDM, which can take into account different weights, should be used in order to make such a classification.

Weights of the evaluation criteria calculated by UTADIS are $g_{4}$ with $27.16 \%$ the most important criterion for according to marginal benefits. Respectively, G-3 criterion is second with $24.58 \%$, g- 2 , is in third place with $24.03 \%$. Finally, criterion is the g_1 has the least weighting criterion, with $23.87 \%$. The total error of the UTADIS model is $41 \%$ and therefore its estimation power is $59 \%$. When classified according to the estimation power of the established UTADIS model, 3 of the countries with a very high HDI value, 30 of the countries with high HDI value, 27 of the countries with middle HDI value and 17 of the countries with low HDI value were classified in a different group than UNDP. As a result, 111 of the 188 countries were classified same as UNDP, while 77 countries were classified differently. According to the results of UTADIS analysis, it has been observed that the class of many countries should change.

\section{Giriș}

1990'ların başlarında ortaya atılan “İnsani Gelişmişlik” kavramı, gelişmişliğin tek başına gelirle açıklanmayacağını göstermiş̧ir. Aynı yıl UNDP tarafindan yürürlüğe giren İnsani Gelişmişlik İndeksi (İGI), ülkelerin gelişmişlik düzeyini belirlemek amacıyla kullanılmaya başlanmıştır. Bunun nedeni, İGİ'nin sadece ekonomik gelişmeyi değil, aynı zamanda insanların yaşam standardının temelini oluşturan sağlık, eğitim ve gelir dağılımını kapsamasıdır. İGİ, bir 
Ülkelerin İnsani Geliş̧mişlik Sinıflamalarının UTADIS Yaklaşımı Aracıllğıyla Yeniden Hesaplanması ve Değerlendirilmesi

ülkenin ortalama başarısını, Yaşam Beklentisi Alt İndeksi ile ölçülen uzun ve sağlıklı bir yaşam; Eğitim Alt İndeksi ile ölçülen bilgi, Gelir Alt İndeksi ile ölçülen iyi bir yaşam standardı olmak üzere üç alt indeks aracılığıyla üç boyutta ölçmektedir. Dolayısıyla, uzun ve sağlıklı bir yaşam boyutu, doğumda yaşam beklentisi göstergesi; bilgi/eğitim boyutu, ortalama okullaşma yılı ve beklenen okullaşma yılı göstergeleri; iyi bir yaşam standardı boyutu, kişi başına düşen Gayri Safi Milli Gelir (GSMG) göstergesi ile belirlenmektedir. UNDP tarafindan yayımlanan İnsani Gelişmişlik Raporları (İGR), içeriğinde yer alan ülkelerin gelişme düzeyi başarısını gösteren ve geçerliliği uluslararası platformda kabul gören bir rapordur. İlki 1990 y1lında olmak üzere her y1l düzenli olarak yayımlanan bu raporlar, tüm ülkeler hakkında geniş kapsamlı istatistikler sunmaktadır. İGR'lerde sunulan İGİ verilerine göre ülkeler "Çok Yüksek", "Yüksek", "Orta" ve "Düşük" gelişmiş̧lik düzeyine sahip ülkeler olmak üzere 4 siralı sinifta kategorize edilmektedir.

Bu çalışmanın amacı, İGİ değerlerine göre 188 ülkeyi Çok Kriterli Karar Verme yöntemlerinden biri olan UTADIS tekniği ile yeniden sınıflandırmaktır. Ayrıca, UNDP tarafından 188 ülkenin İGİ değerlerine göre doğru bir şekilde sıralanıp sıralanmadığı ve ülkelerin doğru grup içinde yer alıp almadığı tespit edilmeye çalışılmıştır. Uygulamada kullanılan UTADIS tekniği, alternatifleri minimum sinıflandırma hatası ile orijinal sinıflarına atayan bir sinıflandırma modelidir. Yani, bir dizi alternatifi önceden tanımlanmış sınıflara ayırmak için kullanılan çok kriterli bir tekniktir. Çalışmanın birinci bölümü İnsani gelişmişlik indeksi kavramını ele almaktadır. İkinci bölümde araştırmada kullanılan UTADIS tekniği detaylı bir şekilde anlatılmaktadır. Üçüncü bölümde literatür taramasına yer verilmektedir. Dördüncü bölümde 188 ülkenin İGİ değerleri üzerinde yapılan UTADIS uygulaması anlatılmakta ve elde edilen bulguların değerlendirilmesi yapılarak sonuçlar detaylı bir şekilde yorumlanmaktadır. Çalışmanın son bölümü ise sonuç ve değerlendirmelerden oluşmaktadır.

\section{2. İnsani Gelișmişlik İndeksi}

İnsani gelişmişlik, insanların tüm potansiyellerini geliştirebilecekleri ve yaşamlarını kendi ihtiyaçları ve ilgi alanları doğrultusunda yönlendirebilecekleri bir ortam yaratmakla ilgilidir (Lind, 2010: 302). Başka bir ifadeyle, insani gelişmişlik, insanların daha uzun, daha sağlıklı ve daha dolu yaşamaları için insani koşulların iyileştirilmesi olarak tanımlanmaktadır (Ranis ve Stewart, 2000: 49). Bu kavram, insani gelişmişliği bir bireyin yaşam kalitesini artırma olarak ifade eden ve bir ekonomist olan Mahbub Ul Haq tarafından geliştirilmiştir (Safari ve Ebrahimi, 2014: 255). Onun amac1, "kalkınma ekonomisinin odağını ulusal gelirden insan merkezli politikalara kaydırmak" idi. Öğrencilik günlerinden arkadaşı olan Amartya Sen'den ekonomik ilerlemenin yanı sıra refah alanındaki diğer ilerlemelere de odaklanan bir insani gelişmişlik indeksinin geliştirilmesi için yardım istedi (Tofallis, 2013: 1326). Sen'e göre insani gelişmişlik kendi yaşamını şekillendirmek için iyi bir yaşam standardı ve 
özgürlük sağlamanın yanı sıra makul derecede sağlıklı ve güvenli bir hayatın tadını çıkarmaktır (Sen, 2001: 253). İnsanların gerçek özgürlüklerini merkeze koyan ve yeni bir kavram olarak 1990'ların başlarında ortaya çıkan bu yeni yaklaşım insani gelişmişlik olarak adlandırılmıştır.(Radovanović, 2011: 195).

Birleşmiş Milletler (UN), İnsani Gelişmişlik İndeksi'ni 1975'te hesaplamaya başlamış ve 1990 yılında da ilk İnsani Gelişmişlik Raporu'nu yayımlamıştır. Raporun temeli, bir ülkenin gelişme refahını ölçmek için gerekli koşulları iyileştirmeye dayanmaktadır (Hou, Walsh ve Zhang, 2015: 332). 1990 yılında hazırlanan ilk İGR'de 130 ülke için İGİ değeri hesaplanmıştır. Daha sonraki yıllarda yeni ülkeler eklenerek bu sayı en son hazırlanan 2016 yılı İGR'de 188 ülkeye çıkarılmıştır (Demir, 2006: 5).

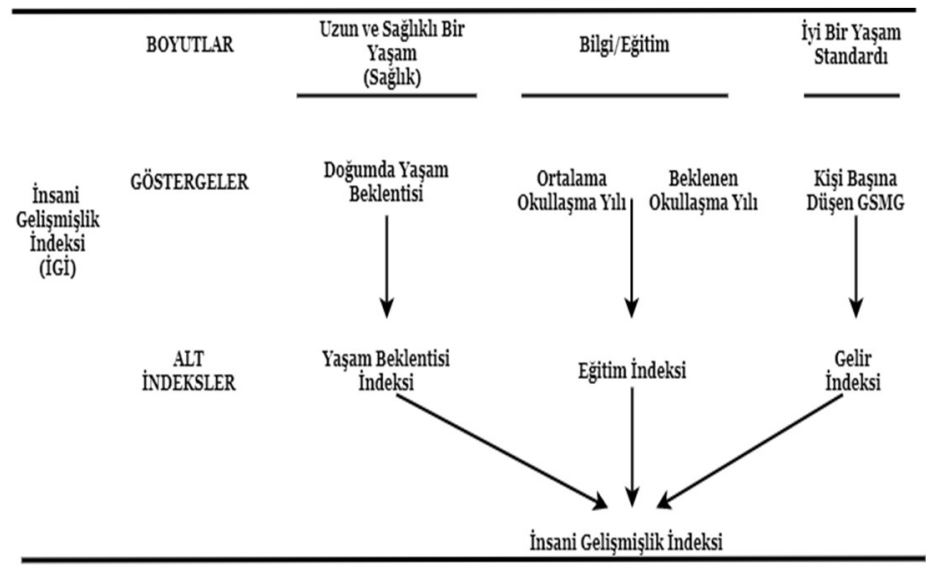

Kaynak: (UNDP, 2010: 215)

Şekil 1. İnsani Gelişmişlik İndeksinin Oluşumu (2010 ve sonrası)

Şekil 1'de, UNDP'nin indeksi hesaplamak için kullandığı boyutlar, göstergeler ve alt indeksler gösterilmektedir. İnsani gelişmişlik, insan yaşamının üç temel bileşen üzerinde odaklanması gerektiğini ifade etmektedir. Bunlar; Uzun ve Sağlıklı Bir Yaşam, Bilgi/Eğitim ve Kişi Başına Düşen Gayri Safi Milli Gelir'dir (UNDP, 1990: 11). Doğumda yaşam beklentisi, uzun ve sağlıklı bir yaşamı ölçmek; ortalama okullaşma yılı ve beklenen okullaşma yılı eğitimi ölçmek; kişi başına düşen GSMG, iyi bir yaşam standardını belirlemek amacıyla kullanılmaktadır (Altaş ve Arikan, 2015: 129). İGR'lerin 2010 yılı baskısına kadar İGI, bu üç değişkenin normalleştirilmiş değerlerinin aritmetik ortalaması olarak hesaplanmıştır (Herrero, Martínez ve Villar, 2012: 248). İGİ, uluslararası veri kuruluşlarından her yıl düzenli olarak sağlanan halihazırdaki verilerle hesaplanmaktadır. Bu verilere ulaşılan zaman ile İGR'nin yayımlandığı zaman arasında genellikle iki yıl vardır (Nartgün, Kösterelioğlu ve Sipahioğlu, 2013: 81). İGI'nin hesaplanmasında ilk dönemler aritmetik ortalama kullanılmasına rağmen, mevcut İGI, geometrik ortalama ile hesaplanmaktadır (Aguña ve Kovacevic, 2010: 10) 
Ülkelerin İnsani Geliş̧mişlik Sinıflamalarının UTADIS Yaklaşımı Aracıllğıyla Yeniden Hesaplanması ve Değerlendirilmesi

İGİ'nin yaygın kullanımına rağmen, UNDP tarafindan dikkate alınan boyutlar ve metodoloji hakkında pek çok eleştiri mevcuttur (do Carvalhal Monteiro, Pereira ve Costa, 2018: 418). UNDP, 1990 yılında yayımlanan İGR'de veri kullanılabilirliği ve tutarlılığ ile ilgili problemi kabul ederek, daha spesifik olarak, yetersiz veri, eksik ülke kapsamı, veri kümelerinde güvenilirlik ve zaman çizelgeleri eksikliği gibi sorunlara dikkat çekmiştir (Bagolin ve Comim, 2008: 19,20). 2009 ve 2010 İGR'lerin baş yazarı değişkenlere eşit ağılık verilmesini eleştirmiştir. Bu eleştiri, İGİ'nin (1997) mimarlarından olan Anand ve Sen tarafindan da değişkenlere herhangi bir ağırlık verilmesinin kamusal olarak tartışmaya açık olması gerektiği şeklinde onaylanmıştır (Tofallis, 2013: 1329). İGI'ye yönelik bir başka eleştiri ise üç bileşenli indekslerin rastgele bir ağırlıklandırma yani basit bir ortalama kullanmasıdır (Nguefack-Tsague, Klasen ve Zucchini, 2011: 184).

\section{UTADIS Tekniği}

Birçok açıdan problem olarak görülen karar verme, mevcut seçenekler arasından en iyi olanı tercih etme olarak ifade edilebilir (Tunca ve diğ., 2016: 2). Karar problemi ise, bir karara varmak için birtakım kriterler üzerinde bir dizi potansiyel alternatifin incelenmesini içermektedir. (Zopounidis ve Doumpos, 1999b: 197). Karar analizi teknikleri genel olarak 3 grupta sınıflandırılmaktadır. Bunlar; Tek Amaçlı Karar Verme (TAKV), Karar Destek Sistemleri (KDS) ve Çok Kriterli Karar Verme (ÇKKV)'dir. Karar Analizi tekniklerinin sinıflandırılması Şekil 2'de özetlenmektedir (Zhou, Ang ve Poh, 2006: 2605).

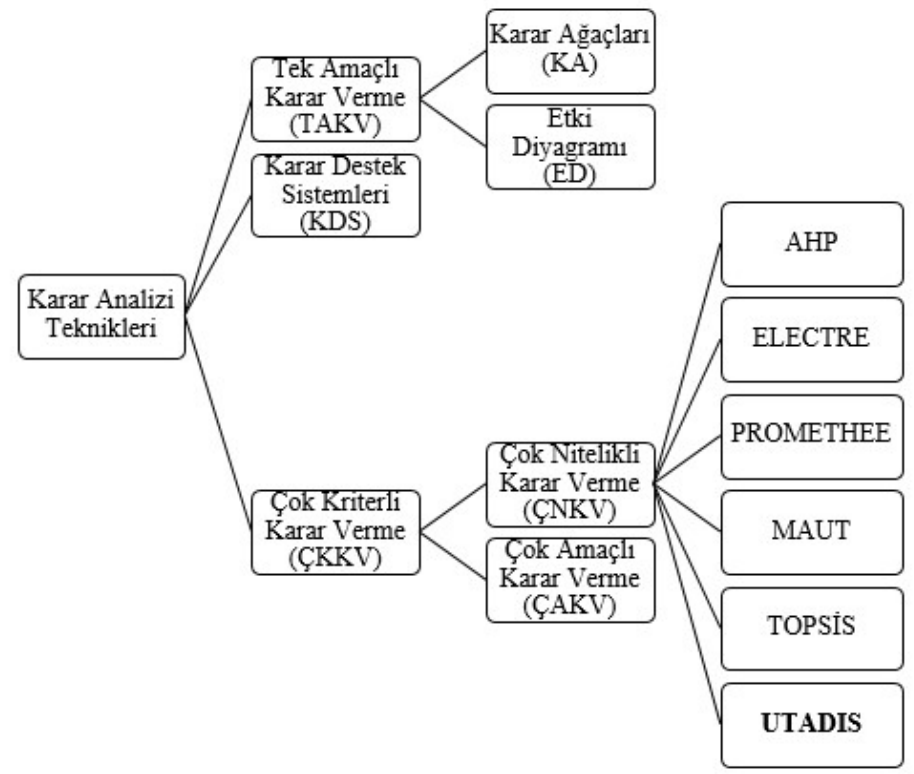

Kaynak: (Zhou ve diğ., 2006: 2606)

Şekil 2. Karar Analizi Tekniklerinin Sinıflandırılması 
ÇKKV, karar vericilere sınırlı sayıda alternatif arasından birden fazla bakış açısı sağlayarak en iyi öneride bulunmayı amaçlayan metodolojik bir çerçevedir (Manshadi, Mehregan ve Safari, 2015: 34).

İlk kez Devaud, Groussaud, Jacquet-Lagreze (1980) tarafindan ortaya atılan ve Jacquet - Lagreze ve Siskos (1982) ve Jacquet - Lagreze (1995) tarafindan yapılan çalışmalarla ileriye götürülen ve sıralama problemlerinde ilave fayda fonksiyonları oluşturmak amacıyla kullanılan UTADIS tekniği, UTA yönteminden türeyerek ortaya çıkmış bir yaklaşımdır (Zopounidis ve Doumpos, 1999b: 198). UTADIS tekniği, alternatifler ve sınıfları ayırmada kullanılan fayda eşikleri arasında karşılaştırma yapar. Böylece, alternatifler orjinal sınıflarında minimum yanlış sınıflandırma hatasıyla sınıflandırılabilir (Zopounidis ve Doumpos, 1997: 17). Ayrıca UTADIS, yanlış sınıflandırma hatalarını (mesafeler bakımından) en aza indirmenin, yanlış sınıflandırma sayısını da en aza indireceği varsayımıyla, yanlış sınıflandırılmış alternatiflerin sayısını dolaylı olarak en aza indirir (Zopounidis ve Doumpos, 1997: 18).

UTADIS tekniği, etkili bir şekilde sınıflandırma ve sıralama problemlerini değerlendirmek için kullanılmaktadır. Bir kriter toplama modeli geliştirilerek alternatiflerin sıralandığı teknikte, alternatiflerin atandığı sınıflar arasında bir tercih ilişkisi vardır. Birinci sınıftaki alternatifler grubu en yüksek puanları alırken, son sınıftaki alternatiflerin puanları düşmektedir (Duman, 2010: 26). UTADIS yaklaşımının amacı, minimum sınıflandırma hatasıyla önceden tanımlanmış homojen gruplardaki bir dizi alternatifin sınıflandırılması için bir ilave fayda modeli geliştirmektir (Diakoulaki ve diğ., 1999: 159).

Çok Nitelikli Karar Verme yöntemlerinden biri olan UTADIS tekniği, 1990'lı yılların ortasında Çok Kriterli Karar Analizi üzerine çalışan araştırmacıların dikkatini çekmiştir. Araş̧ırma ve geliştirme projelerinin değerlendirilmesi amaciyla 1995 yılında Jacquet - Lagreze tarafından kullanılan teknik, $1997^{\prime}$ den sonra finansal alanda siniflama yapmak amaciyla kullanılmaya başlanmıştır. FINCLAS (Zopounidis ve Doumpos, 1998) ve PREFDIS (Zopounidis ve Doumpos, 2000) gibi çok kriterli karar destek sistemlerinde de uygulanmıştır (Ulucan ve Atıcı, 2009: 143).

UTADIS tekniğinde, $n$ adet alternatiften oluşan ve $A=\left\{a_{1}, a_{2}, \ldots, a_{n}\right\}$ şeklinde ifade edilen $A$ alternatif kümesi ile $m$ adet değerlendirme kriterden oluşan ve $g_{1}, g_{2}, \ldots, g_{m}$ olarak gösterilen bir kriter kümesi vardır. Alternatifler karar verici tarafından bazı yönleri gözönünde bulundurularak $C_{1}, C_{2}, \ldots, C_{Q}\left(C_{k}\right.$, $C_{k+1}$ 'e tercih edilir, $\left.k=1,2, \ldots, Q-1\right)$ şeklinde $Q$ adet siralı sinıfa ayrilır (Diakoulaki ve diğ., 1999: 159). Değerlendirme kriterleri, bu kriterlerin genel değerlendirmelerini etkileyen alternatiflerin tüm özelliklerini (niteliksel ve/veya niceliksel) içerir (Zopounidis ve Doumpos, 1999a: 1139).

Gruplar arasındaki tercih ilişkisi (1)'deki gibidir:

$$
C_{1} P C_{2} \ldots, C_{Q-1} P C_{Q}
$$


Ülkelerin İnsani Geliş̧mişlik Sinıflamalarının UTADIS Yaklaşımı Aracıllğıyla Yeniden Hesaplanması ve Değerlendirilmesi

$\boldsymbol{P}$, bir grubun diğerine mutlak tercihini yani gruplar arasındaki mutlak tercih ilişkisini göstermektedir (Dimitras, 2001: 2). Gruplama işlemi, en iyi alternatiflerin birinci grupta ve en kötü alternatiflerin $Q$ grubunda yer alması şekilde yapılır. Dolayısıyla, birinci grup $C_{1}$, ikinci grup $C_{2}$ 'ye tercih edilmektedir (Ulucan ve Atıcı, 2009: 144). Alternatiflerin sınıflandırılması için kullanılan bir kriter toplama modeli geliştirilmeli ve tüm kriterler için her bir alternatifin genel performansı değerlendirilmelidir. Kriter toplama modeli, ilave fayda fonksiyonu ile ifade edilmektedir:

$$
U(g)=\sum_{i=1}^{m} p_{i} u_{i}\left(g_{i}\right)
$$

$g=\left(g_{1}, g_{2}, \ldots, g_{m}\right)$ değerlendirme kriterlerinin vektörüdür. $p_{i}$, kriterin önemini belirten bir ölçeklendirme sabitidir. $u_{i}\left(g_{i}\right)$, kriterin marjinal fayda fonksiyonudur (Manshadi ve diğ., 2015: 36). Ayrıca, $p_{i} \geq 0$ kriter ağırlığıdır $\left[g_{i}\left(p_{1}+p_{2}+\right.\right.$ $\left.\left.\cdots+p_{m}=1\right)\right] . u_{i}\left(g_{i}\right), 0$ ile 1 arasında normalize edilmiş marjinal fayda fonksiyonudur (Spathis, Doumpos ve Zopounidis, 2003: 282). Global fayda, $[0,1]$ aralığındadır. Sınıflandırma işlemi, 0 ve 1 arasında fayda ölçeğinde tanımlanan kesim noktası ile her bir alternatifin global faydasını karşılaştırılarak gerçekleştirilir. Global faydası, fayda kesim noktasından daha yüksek olan alternatifler $C_{1}$ grubuna atanırken, global faydası fayda kesim noktasından daha düşük olan alternatifler $C_{2}$ grubuna atanır (Manshadi ve diğ., 2015: 36). Başka bir ifadeyle, sınıflandırma, sınıfları ayıran fayda eşikleri ile onların global faydalarının karşılaştırılmasıyla yapılır. Genel olarak, $\left(C_{1}, C_{2}, \ldots, C_{Q}\right)$ şeklinde $Q$ adet sınıftan oluşan bir grupta sıralama, en iyi sınıftan $\left(C_{1}\right)$, en kötü olana $\left(C_{Q}\right)$ doğru yapılır. Sınıflandırmayı gerçekleştirmek için gerekli olan fayda eşik sayısı $Q-1$ 'dir (Voulgaris, Doumpos ve Zopounidis, 2000: 130).

Marjinal fayda fonksiyonları, $u_{i}\left(g_{i^{*}}\right)=0$ ve $u_{i}\left(g_{i}^{*}\right)=1$ koşullarının yerine getirilmesiyle kriter ölçeğinde tanımlanan monoton fonksiyon özelliği taşımaktadırlar (doğrusal veya doğrusal olmayan) (Kosmidou, Doumpos ve Zopounidis, 2008: 20). Marjinal fayda fonksiyonları, kriter ölçeğini $[0,1]$ aralığında yeni bir ölçeğe dönüştürecek bir sistem sağlamaktadır. Bu yeni ölçek, her bir kriter değerinin, karar verici için faydasını temsil etmektedir (Kosmidou ve diğ., 2008: 21).

UTADIS yönteminde geliştirilen ilave fayda fonsiyonu ile alternatiflerin her birine bir puan atanır. Bu puan (global fayda), 0 ve 1 arasında bir fayda/değer ölçeğinde tüm kriterler için her bir alternatifin genel performansını ölçer. Global fayda ne kadar yüksekse, alternatif performansı da o kadar yüksek olacaktır. Global fayda, $p_{i}$ kriter ağırlıkları ve alternatiflerin her bir kriter üzerindeki performansı dikkate alınarak hesaplanmaktadır. Kriter ağırlıkları 1'e kadar çıkmaktadır ve geliştirilen sınıflandırma modelinde her bir kriterin önemini göstermektedirler. Diğer taraftan, marjinal fayda fonksiyonları $u_{i}\left(g_{i}\right)$, her bir alternatifin $g_{i}$ kriteri üzerinde kısmi performansını belirlemek için 
kullanılmaktadır. Marjinal faydalar kriter ölçeğinin fonksiyonlarıdır ve 0 ile 1 aralığında değerler alırlar (Doumpos ve Zopounidis, 2002: 306).

$G_{i}=\left[g_{i^{*}}, g_{i}^{*}\right]$ aralığ 1 her değerlendirme kriteri $g_{i}$ için tanımlanır. $g_{i^{*}}$ ve $g_{i}^{*}$ sırasıyla $g_{i}$ kriteri için $A$ setinde yer alan bütün alternatifler içinden en az tercih edilen ve en çok tercih edilen değerlerdir. $G_{i}$ aralığ $a_{i}-1$ eşit aralığa $\left(\left[g_{i}^{j}, g_{i}^{j+1}\right], j=1,2, \ldots, a_{i}-1\right)$ bölünür. $G_{i}$ 'nin kaç alt aralığa bölüneceği yani $a_{i}-1$ değeri karar verici tarafindan belirlenir. Bu değer, her marjinal fayda $u_{i}$ için tahmini noktaların sayısını ifade etmektedir (Zopounidis ve Doumpos, 1999b: 200). Daha güvenilir sonuçlar elde etmek için alt aralık sayısının alternatif sayısına yakın belirlenmesi veri seti ile marjinal fayda ölçeğini yakınlaştıracaktır. Fakat, bu durum modelin gereğinden fazla büyümesine neden olur. Bu nedenle, alt aralık sayısı alternatif sayısına çok yakın bir değer olmamalıdır. Genellikle, ortalama bir değer belirlenmesi önerilmektedir (Ulucan ve Atıc1, 2009: 145).

Alt aralıkları belirleyen, her bir nokta, doğrusal enterpolasyon ile (2)'deki gibi hesaplanır (Zopounidis ve Doumpos, 1999b: 200):

$$
g_{i}^{j}=g_{i^{*}}+\frac{j-1}{a_{i}-1}\left(g_{i}^{*}-g_{i^{*}}\right)
$$

Amaç, bu noktaların her biri için alternatiflerin marjinal faydalarını tahmin etmektir. Alternatif $a^{\prime}$ 'nı $g_{i}$ kriteri üzerindeki değeri $g_{i}(a)$ 'dır ve bu durum $g_{i}(a) \in\left[g_{i}^{j}, g_{i}^{j+1}\right]$ şeklinde ifade edilir. $a$ alternatifinin marjinal faydası $u_{i}\left[g_{i}(a)\right]$, doğrusal enterpolasyon ile (3)'teki gibi hesaplanır (Zopounidis ve Doumpos, 1999b: 200):

$$
u_{i}\left[g_{i}(a)\right]=u_{i}\left(g_{i}^{j}\right)+\frac{g_{i}(a)-g_{i}^{j}}{g_{i}^{j+1}-g_{i}^{j}}\left[u_{i}\left(g_{i}^{j+1}\right)-u_{i}\left(g_{i}^{j}\right)\right]
$$

Kriterlerin monotonluğunu sağlamak için (4)'teki kısıtın karşılanması gerekir (Zopounidis ve Doumpos, 1999b: 200):

$$
u_{i}\left(g_{i}^{j+1}\right)-u_{i}\left(g_{i}^{j}\right) \geq 0, \forall i
$$

Monotonluk kısıtı olarak adlandırılan bu kısıt, kriter sayısı ile alt aralık sayısının çarpımından oluşan sayı kadar monotonluk kısıtının modele eklenmesi gerektiğini ifade etmektedir (Ulucan ve Atıc1, 2009: 145).

Monotonluk kısitları, Siskos ve Yannacopoulos (1985) tarafindan geliştirilen UTASTAR yönteminde olduğu gibi, (5) ve (6)'daki dönüşümler aracılığıyla elde edilir:

$$
\begin{gathered}
w_{i j}=u_{i}\left(g_{i}^{j+1}\right)-u_{i}\left(g_{i}^{j}\right) \geq 0, \forall i, j \\
u_{i}\left(g_{i^{*}}\right)=0 \\
u_{i}\left(g_{i}^{j}\right)=\sum_{k=1}^{j-1} w_{i k}
\end{gathered}
$$


Ülkelerin İnsani Geliş̧mişlik Sinıflamalarının UTADIS Yaklaşımı Aracıllğıyla Yeniden Hesaplanması ve Değerlendirilmesi

$w_{i j}$, artık değişkenlerdir ve iki ardışık kesim noktasının marjinal faydaları arasındaki farkı temsil etmektedir. $\mathrm{Bu}$ artık değişkenler modele sonradan eklenmektedir (Ulucan ve Atıc1, 2009: 146).

(5) ve (6)'daki dönüşümler yapıldıktan sonra, (3)'teki $u_{i}\left(g_{i}^{j}\right)$ yerine $\sum_{k=1}^{j-1} w_{i k}$ ve $\left[\left(g_{i}^{j+1}\right)-u_{i}\left(g_{i}^{j}\right)\right]$ yerine $w_{i j}$ getirilerek bir alternatifin marjinal faydasını gösteren fonksiyon (7)'deki eşitlik ile elde edilebilir (Zopounidis ve Doumpos, 1999b: 201):

$$
u_{i}\left[g_{i}(a)\right]=\sum_{k=1}^{j-1} w_{i k}+\frac{g_{i}(a)-g_{i}^{j}}{g_{i}^{j+1}-g_{i}^{j}} w_{i j}
$$

Alternatifleri orijinal sınıflarında sıralamak için UTADIS yöntemi ile geliştirilen ilave fayda modeli (8)'deki gibi ifade edilmektedir.

$$
U(a)=\sum_{i=1}^{m} u_{i}\left[g_{i}(a)\right]
$$

$U(a), a \in A$ olmak üzere değerlendirme kriteri $g_{i}$ için bir alternatifin global faydasını ve $u_{i}\left[g_{i}(a)\right]$ ise $a \in A$ olmak üzere değerlendirme kriteri $g_{i}$ için bir alternatifin marjinal faydasın ifade etmektedir. Yani, $U(a)$ alternatiflerin global faydası ise her bir kriter için marjinal faydalarının toplamını göstermektedir. Alternatifleri orjinal sinıflarında sınıflandırmak için $u_{1}, u_{2}, \ldots, u_{Q-1}$ fayda eşiklerinin hesaplanması gerekir. (Eşik $u_{k}, C_{k}$ ve $C_{k+1}$ sinıflarını ayırmaktadır $\forall k \leq Q-1$ ) (Diakoulaki ve diğ., 1999: 159). Bir alternatifin marjinal faydas1, modeldeki kriterlerin nispi önemini temsil etmektedir (Dimitras, 2001: 2).

(9) ve (10)'da gösterilen kisitlar modelde yer alan normalizasyon kısıtlarıdır. Alternatiflerin marjinal faydalarının toplamının üst sınırını ve alt sınırını sırasıyla 1 ve 0 'a eşitleyen kısıtlardır. Yani, 0 ile 1 aralığında bir ölçekte global faydaların değer almasını sağlayan kısıtlardır. Normalizasyon kısıtları,

$$
\begin{gathered}
\sum_{i=1}^{n} u_{i}\left(g_{i}^{*}\right)=1 \\
\sum_{i=1}^{n} u_{i}\left(g_{i^{*}}\right)=0
\end{gathered}
$$

şeklinde gösterilmektedir (Ulucan ve Atıc1, 2009: 146). (9) ve (10)'daki normalizasyon kısıtları, modelde yapılan dönüşümler ve $w_{i j}$ artık değişkenlerinin modele eklenmesi ile (11) ve (12)'deki eşitlikler elde edilir. Ayrıca, (10)'daki kısıt modelden çıkarılarak, (9)'daki normalizasyon kısıtı (13)'deki gibi modele eklenen $w_{i j}$ değişkenleri ile ifade edilmektedir. Bahsedilen dönüşümler yapıldıktan sonra, 


$$
\begin{gathered}
u_{i}\left(g_{i^{*}}\right)=0 \\
u_{i}\left(g_{i}^{*}\right)=\sum_{k=1}^{a_{i}-1} w_{i k} \\
\sum_{i=1}^{m} \sum_{j=1}^{a_{i}-1} w_{i j}=1
\end{gathered}
$$

eşitlikleri elde edilmektedir (Ulucan ve Atıc1, 2009: 147). Global fayda $U(a)$ ile ilişkili iki tür yanlış sınıflandırma hatası vardır. Bunlar, fazla tahmin hatası $\sigma^{+}(a)$ ve eksik tahmin hatas $\sigma^{-}(a)$ 'dır. Fazla tahmin hatas1 $\sigma^{+}(a)$, bir alternatifin fayda değerine göre ait olduğu sınıftan daha düşük bir sınıfta yer alması (örneğin, $C_{1}$ sinifina ait olan bir alternatifin $C_{2}$ sinifinda yer almasi) durumunda ortaya çıkmaktadır. Böyle bir durumda, doğru bir sınıflandırma yapmak için $\sigma^{+}(a)$ hata miktarının bu alternatifin global fayda fonksiyonuna eklenmesi gerekmektedir. Eksik tahmin hatası $\sigma^{-}(a)$ ise bir alternatifin fayda değerine göre ait olduğu sınıftan daha üst bir sınıfta yer alması (örneğin, $C_{2}$ sınıfina ait olan bir alternatifin $C_{1}$ sinıfında yer alması) durumunda ortaya çıkmaktadır. Böyle bir durumda, doğru bir sınıflandırma yapmak için $\sigma^{-}(a)$ hata miktarının bu alternatifin global fayda fonksiyonundan çıkarılması gerekmektedir (Zopounidis ve Doumpos, 1999b: 201). Bu iki tip hata şekil 3'de gösterilmektedir.

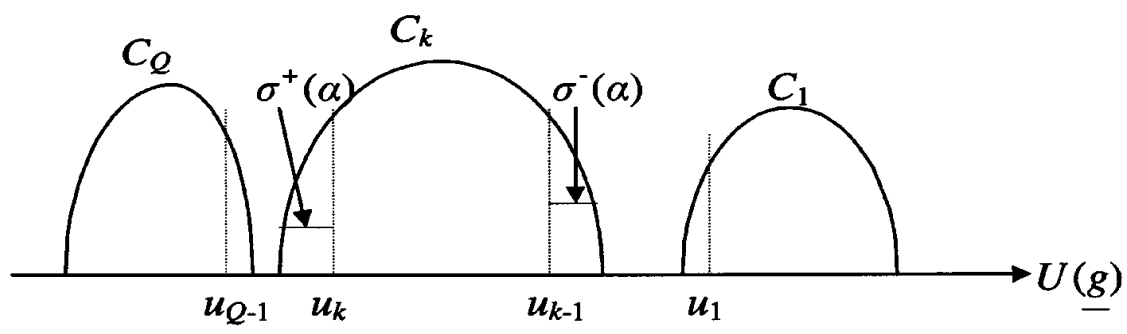

Kaynak: (Zopounidis ve Doumpos, 1999b: 201)

Şekil 3. Sinıfların Fayda Üzerindeki Dă̆ılımı

Alternatifleri orijinal sınıflarına ayırmak için, $u_{1}, u_{2}, \ldots, u_{Q-1}$ şeklinde ifade edilen fayda eşiklerini tahmin etmek gerekmektedir $\left(u_{k}\right.$ fayda eşiği, $C_{k}$ ve $C_{k+1}$ sınıflarını, $\forall k \leq Q-1$ koşulu ile ayırmaktadır) (Zopounidis ve Doumpos, 2000: 782). Alternatiflerin sinıflandırılması, her bir global faydanın, bir sinıfi diğerinden ayıran $u_{i}\left(u_{1}>u_{2}>\cdots>u_{Q-1}\right)$ şeklindeki uygun fayda eşikleri ile karşılaştırılması yoluyla gerçekleştirilmektedir. Fayda eşikleri ile alternatiflerin global faydaları arasındaki ilişkilere göre alternatifler (14), (15), (16) ve (17)'deki gibi sinıflandırılmaktadır (Zopounidis ve Doumpos, 1999b: 201). Dolayisıyla, alternatiflerin global faydalarının fayda eşikleri ile karşılaş̧ırılması yoluyla, 
Ülkelerin İnsani Geliş̧mişlik Sinıflamalarının UTADIS Yaklaşımı Aracıllğıyla Yeniden Hesaplanması ve Değerlendirilmesi

$$
\begin{gathered}
U(a) \geq u_{1} \Rightarrow a \in C_{1} \\
U_{2} \leq U(a)<u_{1} \Rightarrow a \in C_{2} \\
U_{k} \leq U(a)<u_{k-1} \Rightarrow a \in C_{k} \\
U(a)<u_{Q-1} \Rightarrow a \in C_{Q}
\end{gathered}
$$

şeklinde alternatiflerin sınıflandırılması işlemi gerçekleştirilir (Diakoulaki ve diğ., 1999: 159).

Doğrusal programlama formülasyonu, ilave fayda fonksiyonunu ve fayda eşiklerini tahmin etmek amacıyla kullanılmaktadır. Böylece, yapılan sınıflandırma işlemindeki tüm hataların toplamı, modeldeki $(14,15,16$ ve 17$)$ tüm alternatifler için minimum düzeye indirilecektir (Gaganis, Pasiouras ve Zopounidis, 2006: 171).

(8)'deki global fayda fonksiyonunun tanımı ve açıklanan iki tip hata payı dikkate alınarak yukarıdaki eşitsizlikler,

$$
\left.\begin{array}{cc}
\sum_{i=1}^{m} u_{i}\left[g_{i}(a)\right]-u_{1}+\sigma^{+}(a) \geq 0 & \forall a \in C_{1} \\
\sum_{i=1}^{m} u_{i}\left[g_{i}(a)\right]-u_{k-1}-\sigma^{-}(a) \leq-\delta \\
\sum_{i=1}^{m} u_{i}\left[g_{i}(a)\right]-u_{k}+\sigma^{+}(a) \geq 0
\end{array}\right\} \begin{aligned}
& \forall a \in C_{k} \\
& \sum_{i=1}^{m} u_{i}\left[g_{i}(a)\right]-u_{Q-1}-\sigma^{-}(a) \leq-\delta
\end{aligned} \forall A \in C_{Q}
$$

(18), (19) ve (20)'deki gibi ifade edilebilirler (Zopounidis ve Doumpos, 1999b: 202).

(19) ve (20)'deki $\delta$ değeri global fayda değeri $U(a)$ 'nın $u_{k-1}\left(a \in C_{k}, k>\right.$ 1 olduğ $u$ durumlarda ) ve $u_{Q-1}\left(a \in C_{Q}\right.$ olduğu durumlarda) değerleri ile mutlak eşitsizliğini sağlamak için kullanılan çok küçük, pozitif bir reel sayı değeridir. Amaç $u_{i}\left[g_{i}(a)\right]$ marjinal faydalarının ve $u_{k}$ fayda eşiklerinin (18), (19) ve (20)'deki kısıtları sağlayacak ve tüm hataların toplamını minimize edecek şekilde belirlenmesidir (Zopounidis ve Doumpos, 1999b: 202).

Global fayda modelinin (ilave fayda fonksiyonunun) ve fayda eşiklerinin tahminleri, aşağıdaki doğrusal programın çözümü ile gerçekleştirilmektedir (Diakoulaki ve diğ., 1999: 160). Bu koşullar altında UTADIS tekniğinin modeli aşağıda gösterilen şekilde oluşmaktadır:

$$
\text { Minimize } F \sum_{a \in C_{1}} \sigma^{+}(a)+\cdots+\sum_{a \in C_{k}}\left[\sigma^{+}(a)+\sigma^{-}(a)\right]+\cdots+\sum_{a \in C_{Q}} \sigma^{-}(a)
$$

Kisitlar: 


$$
\begin{aligned}
& \sum_{i=1}^{m} u_{i}\left[g_{i}(a)\right]-u_{1}+\sigma^{+}(a) \geq 0 \quad \forall a \in C_{1} \\
& \left.\begin{array}{c}
\sum_{i=1}^{m} u_{i}\left[g_{i}(a)\right]-u_{k-1}-\sigma^{-}(a) \leq-\delta \\
\sum_{i=1}^{m} u_{i}\left[g_{i}(a)\right]-u_{k}+\sigma^{+}(a) \geq 0
\end{array}\right\} \forall a \in C_{k} \\
& \sum_{i=1}^{m} u_{i}\left[g_{i}(a)\right]-u_{Q-1}-\sigma^{-}(a) \leq-\delta \quad \forall a \in C_{Q} \\
& \sum_{i=1}^{m} \sum_{j=1}^{a_{i}-1} w_{i j}=1 \\
& u_{k-1}-u_{k} \geq s \quad k=2,3, \ldots, Q-1 \\
& w_{i j} \geq 0, \quad \sigma^{+}(a) \geq 0, \quad \sigma^{-}(a) \geq 0
\end{aligned}
$$

$C_{1}, C_{2}, \ldots, C_{Q} ; C_{1}$ en iyi alternatifin olduğu grubu ve $C_{2}$ en kötü alternatifin olduğu grubu göstermek üzere $\mathrm{Q}$ tane önceden tanımlanmış sıralı sınıfa ayrılır. $u_{1}, u_{2}, \ldots, u_{Q-1}$; grupları ayıran fayda eşikleridir. Yani, fayda eşiği $u_{k}, C_{k}$ ve $C_{k+1}$ gruplarını ayırır $(\forall k \leq Q-1) . \sigma^{+}(a)$ ve $\sigma^{-}(a)$; yanlış sınıflandırma hatalarıdır. $s ; u_{k-1}>u_{k}(s>0)$ eşitliğini sağlamak için kulllanılan eşik değeridir (Zopounidis ve Doumpos, 1997: 17). $\delta$ ise $\sum_{i=1}^{m} u_{i}\left[g_{i}(a)\right]<$ $u_{k-1}, \forall a \in C_{k}, 2 \geq k \leq Q-1(\delta>0)$ eşitliğini sağlamak için kullanılan bir eşik değeridir (Zopounidis ve Doumpos, 1997: 18). Bu durumda, $a_{i}, g_{i}$ kriterinin değer aralığının bölünmüş olduğu $\left[g_{i}^{j}, g_{i}^{j+1}\right]$ alt aralık sayısını, $w_{i j}=$ $u_{i}\left(g_{i}^{j+1}\right)-u_{i}\left(g_{i}^{j}\right) ; g_{i}\left(w_{i j} \geq 0\right)$ kriterinin iki ardışık $g_{i}^{j}$ ve $g_{i}^{j+1}$ değerlerinin marjinal faydaları arasındaki farkı; $\delta, U_{(a)}<u_{k-1}, \forall a \in C_{k}, 2 \leq k \leq Q-$ $1(\delta>0)$ eşitliğini sağlamak için kullanılan bir eşik değerini; $s, u_{k-1}>u_{k}(s>$ $\delta>0)$ eşitliğini sağlamak için kullanılan bir eşik değerini, $\sigma^{+}(a)$ ve $\sigma^{-}(a)$ sırasıyla fazla ve eksik tahmin hatalarını ifade etmektedir (Diakoulaki ve diğ., 1999: 160).

(26)'da yer alan kısıttaki s parametresi, sınıfları birbirinden ayıran fayda eşikleri arasındaki mutlak tercih ilişkisini sağlamak için modele eklenmiş bir parametredir. Özet olarak, önceden tanımlanmış gruplardaki alternatiflerin global fayda puanlarının hesaplanarak, alternatiflerin 0 ile 1 arasında değişen yeni bir ölçeğe taşınması ve hatanın minimum olacağı şekilde grup eşiklerinin belirlenmesi UTADIS tekniğinin amacıdır. Bu amacı gerçekleștirmek için (21), (22), (23), (24), (25), (26) ve (27) ile belirtilen matematiksel model çözülerek sonuca ulaşılmaktadır (Ulucan ve Atıcı, 2009: 150).

\section{Literatür Özeti}

Ogwang (1994) çalışmasında, Jolliffe $(1972,1973)$ tarafından tartışılan değişken seçim stratejisini kullanarak, İGI'nin üç bileşenini en iyi temsil eden 
Ülkelerin İnsani Geliş̧mişlik Sinıflamalarının UTADIS Yaklaşımı Aracıllğıyla Yeniden Hesaplanması ve Değerlendirilmesi

değişkeni belirlemeye çalışmıştır. Bu amaçla, 1993 İGR'den alınan 173 ülkeye ait veri kullanılmıştır. Kullanılan değişken seçim stratejisine göre yaşam beklentisinin en iyi seçenek olduğu sonucuna varmıştır. Yaşam beklentisi yoksunluk indeksi 1'den çıkarılarak çok fazla bilgi kaybı olmadan ve daha düşük maliyetle basitleştirilmiş bir İGİ elde edilebileceği görülmüştür. Karabulut, Kaya, Gürsoy (2006) çalışmalarında, 2006 yılı İGİ verilerini kullanarak OECD’ye tam üye statüsünde olan ve tamamı sanayileşmiş ülkeler kategorisinde yer alan 30 ülkenin insani gelişmişlik açısından değerlendirmesini yapmışlardır. Yapılan hesaplamalar sonucunda oluşturulan indeks değerlerinin UNDP tarafindan yayımlanan indeks değerleri ile benzer olduğu bulgulanmıştır. Bu sonuçlara göre; OECD ülkelerinin tamamı yüksek insani gelişmişlik düzeyine sahip iken, Türkiye bu ülkelerin dışında kalmıştır. Eğitim indeksi açısından yüksek insani geliş̧miş̧lik kategorisinde yer alan bunun dışında orta sınıf kategorisinde bulunan Türkiye için okullaşma oranının artmasının ekonomik açıdan olumlu etkiler yaratacağı ve böylece GSYIH'nin artarak refah seviyesini yükselteceği sonucuna varılmıştır. Şahin ve Gökdemir (2016) çalışmalarında, UNDP tarafından yayımlanan İGİ'yi oluşturan yaşam beklentisi, kişi başına GSMH, ilköğretimde okullaşma oranı, ortaöğretimde okullaşma oranı ve yükseköğretimde okullaşma oranı bileşenlerinden oluşan kısa ve uzun dönem dinamiklerini, 1981-2013 örneklem dönemi için Türkiye ölçeğinde ARDL Sınır Testi ile incelemişlerdir. Uzun dönem dinamikleri En Küçük Kareler Yöntemi ve kısa dönem dinamikleri ise Hata Düzeltme Modeli yardımıyla oluşturulmuştur. Türkiye'nin yüksek bir insani gelişmişlik seviyesine sahip olması için mevcut eğitim ve ekonomi politikalarının iyileştirmesi gerektiği sonucuna varılmıştır. do Carvalhal Monteiro ve diğ. (2018) çalışmalarında, UNDP tarafindan kullanılan boyut ve ağırlıkların temelini kullanan yeni bir İGİ sınıflandırma yöntemi önermişlerdir. Dolayısıyla, UNDP yaklaşımı uygulandığında ortaya çıkabilecek telafi edici etki ve yanlış sınıflandırmadan kaçınmayı amaçlamışlardır. Önerilen yaklaşım ayrıca herhangi bir boyut ve ağırlık seti ile çalışmayı da sağlar. Sınıflandırma işlemi, ÇNKV yöntemlerinden biri olan ELECTRE TRI ile gerçekleştirilmiştir. Önerilen sinıflandırma yöntemi, UNDP tarafindan benimsenen sonuçtan daha iyi sonuçlar elde etmiştir, çünkü ülkeler telafi edici etki olmadan doğal sınıflarında doğru bir şekilde sınıflandırılabilirler. Bununla birlikte, önerilen sınıflandırma yöntemi daha sağlamdır, gerçeğe daha yakındır ve boyutlar arasındaki telafi edici etkiyi ortadan kaldırabilir, böylece İGI'ye daha fazla güvenilirlik sağlayabilir.

Dimitras (2001) çalışmasında, sadece niceliksel olarak değil aynı zamanda birçok uzmanın bilgi birikimini de içeren kategorilerdeki stokların sinıflandırılması için çok kriterli bir yöntem olan UTADIS yöntemini, Atina Menkul Kıymet Borsasındaki inşaat sektörü stokları üzerinde uygulamıştır. Karar verici tarafindan dört kategoriye ayrılan 24 inşaat şirketi üzerinde uygulanan yöntem ile yatırım kararlarını analiz etme ve inşaat sektörü şirketlerinin menkul kıymetlerinin seçiminde kullanılan kriterleri değerlendirme yeteneği sağlanmıştır. Ayrıca, UTADIS yönteminin Atina Menkul Kıymet Borsasındaki 
diğer sektörlerin menkul kıymetleri üzerindeki genişletilmiş uygulaması gerçekleştirilmiştir. Dimitras'a göre özellikle, yöntemin karar destek sistemlerine somutlaştırılması durumunda, yöntem, sistemin finansal hizmetler şirketlerine veya herhangi bir yatırımcıya kârlı öneriler sunma yeteneğini önemli ölçüde güçlendirecektir. Doumpos ve Zopounidis (2002) çalışmalarında, iş başarısızlığ 1 tahmininde Çok Kriterli Karar Destek (MCDA) sınıflandırma yöntemi olan UTADIS ve MHDIS ile doğrusal programlama, doğrusal diskriminant analizi ve lojit analizin performanslarını ve uygulanabilirliğini karşılaştırmışlardır. 1980-1992 dönemi için yarısı başarısız olan 144 ABD firması üzerinde yapılan uygulamada, UTADIS yönteminin iş başarısızlığı tahmin modelinde, tüm yıllarda toplam hata oranı açısından diğer yöntemlerin modellerinden daha iyi sonuçlar verdiği görülmüştür. Ayrıca, UTADIS için ortalama hata oranlarının diğer yöntemlere göre daha düşük olduğu ve doğrusal programlama, doğrusal diskriminant analizi ve logit analizi ile yapılan karşılaştırmada, önerilen iki MCDA sınıflandırma yönteminin, iş başarısızlığını tahmin etmek için geçmişte yaygın olarak kullanılan mevcut tekniklere verimli alternatifler olarak düşünülebileceğini göstermiştir.

Ulucan ve Atıcı (2009) çalışmalarında, Türkiye'de faaliyet gösteren 20 adet elektrik dağıtım şirketini sistem kayıp oranlarına göre üç gruba ayırarak, 6 adet kritere (Hizmet Alanı, Personel Sayısı, Abone Sayıs1, Hat Uzunluğu, Harcama, Dağıtım) göre UTADIS tekniğini uygulamışlardır. 6 adet şirketin hata değerleri sıfırdan farklı olarak bulunmuş ve bu şirketlerin belirlenen ilk gruplardan farklı gruplarda yer alması gerektiği sonucuna varılmıştır. Çolak ve Ulucan (2012) çalışmalarında, 628 mobilya işletmesinden 2007 yılında anket yoluyla elde edilen veri ile mobilya endüstrisinde kârlılığı etkileyen faktörleri belirlemek amacıyla UTADIS analizini kullanmışlardır. Mobilya işletmelerinin kârlılık performanslarına göre gruplanması ve gruplanmayı en iyi açıklayan değişkenlerin belirlenmesi amaçlanmıştır. UTADIS tekniğinin mobilya sektöründe ilk uygulaması olan bu çalışmada, UTADIS modelinin kârlılık oranı yüksek olan işletmeleri \%91 doğrulukla, karlılık oranı düşük olan işletmeleri ise \%83 doğrulukla tahmin ettiği sonucuna ulaşılmıştır. Balla ve diğ. (2014) çalışmalarında, devlet tarafından sınıflandırılmış SCA ve NSCA türündeki bankaları UTADIS tekniği ile tekrar sınıflandırmışlardır. 240 bankayı tesadüfi olarak 10 gruba ayırarak, eğitim için 9 tanesini ve doğrulama için de 1 tanesini kullanmışlardır. Bu örnek üzerinde, UTADIS, diskriminant ve sıralı lojistik regresyon yöntemlerini kullanarak, devlet tarafindan yapılan sınıflandırmaya en yakın yöntemi tespit etmeye çalışmışlardır. UTADIS yönteminin bankaların yaklaşık \%80'ini doğru bir şekilde sınıflandırarak tatmin edici bir doğruluk sağladığı sonucuna varılmıştır.

\section{Uygulama}

$\mathrm{Bu}$ çalışma, UNDP tarafindan yayımlanan 188 ülke üzerinde uygulanmıştır. UNDP, ülkeleri değerlendirmek için "Çok Yüksek", "Yüksek", 
Ülkelerin İnsani Geliş̧mişlik Sinıflamalarının UTADIS Yaklaşımı Aracıllğıyla Yeniden Hesaplanması ve Değerlendirilmesi

"Orta" ve "Düşük" gelişmişlik değerine göre dört gruba ayırmaktadır. Dolayısıyla, indeks değerine göre ülkeler 4 grupta sınıflandırılmıştır. İndeks değeri, 0,8-1 aralığında olan ülkeler birinci grupta yani çok yüksek gelişmişlik düzeyine sahip ülke kategorisinde $\left(C_{1}\right) ; 0,701-0,796$ aralığında olan ülkeler ikinci grupta yani yüksek gelişmişlik düzeyine sahip ülke kategorisinde $\left(C_{2}\right) ; 0,550$ 0,699 aralı̆̆ında olan ülkeler üçüncü grupta yani orta gelişmişlik düzeyine sahip ülke kategorisinde $\left(C_{3}\right) ; 0-0,541$ aralığında olan ülkeler dördüncü grupta yani düşük gelişmişlik düzeyine sahip ülke kategorisinde $\left(C_{4}\right)$ yer almaktadır. Birinci grupta 51, ikinci grupta 55, üçüncü grupta 41 ve dördüncü grupta 41 adet ülke mevcuttur. Ülkeler, UNDP tarafindan indeks değerlerine ve dört kritere göre gruplandırılmıştır. $\mathrm{Bu}$ kriterler, Doğumda Yaşam Beklentisi, Beklenen Okullaşma Yı1ı, Ortalama Okullaşma Yılı ve Kişi Başına Düşen GSMG olarak siralanır.

Bu çalışmada, ülkeleri gelişmişlik düzeylerine göre sınıflandırmak için dört kritere dayalı bir model sunulmuştur. Bu modelin alternatifleri 188 ülkedir. Dört kriter ve İGİ değerlerine göre ülkelerin UTADIS yaklaşımıyla doğru grupları yeniden tespit edilmeye çalışılmıştır. Çalışmada üzerinde durulan hipotez, UNDP tarafından hazırlanan İGR'lerde yer alan 188 ülkenin, İGI değerlerine göre UTADIS modeliyle elde edilen sıralamasının aynı olup olmadığı ve ülkelerin UNDP'nin yaptığı grup içinde yer alıp almadığıdır. Çalışmada UNDP tarafından 2017 yılında yayımlanan 2016 yılına ait İnsani Gelişmişlik Raporu'nda yer alan 188 ülkenin verileri kullanılmıştır.

- UTADIS Analizi İle İlgili Bulguların Değerlendirilmesi

UTADIS uygulaması için kullanılan değerlendirme kriterleri Tablo 1'de gösterilmiştir.

Tablo 1. UTADIS Uygulaması Değerlendirme Kriterleri

\begin{tabular}{l|c}
\hline & Değerlendirme Kriterleri \\
\hline $\boldsymbol{g}_{\mathbf{1}}$ & Doğumda Yaşam Beklentisi \\
$\boldsymbol{g}_{\mathbf{2}}$ & Beklenen Okullaşma Y11 \\
$\boldsymbol{g}_{3}$ & Ortalama Okullaşma Y11 \\
$\boldsymbol{g}_{\mathbf{4}}$ & Kişi Başına Düşen GSMG \\
\hline
\end{tabular}

188 ülkenin indeks değerlerine ve değerlendirme kriterlerine ilişkin tanımlayıcı istatistikler Tablo 2'de verilmiştir.

Tablo 2. Tanımlayıcı Istatistikler

\begin{tabular}{c|ccccccc}
\hline & $\begin{array}{c}\text { Gözlem } \\
\text { Sayısı }\end{array}$ & Minimum & Maksimum & Ortalama & $\begin{array}{c}\text { Standart } \\
\text { Sapma }\end{array}$ & Çarpıklık & Basıklık \\
\hline íGi & 188 & 0,352 & 0,949 & 0,69886 & 0,155151 & $-0,363$ & $-0,907$ \\
$\boldsymbol{g}_{\mathbf{1}}$ & 188 & 48,90 & 84,20 & 71,3543 & 8,29484 & $-0,667$ & $-0,242$ \\
$\boldsymbol{g}_{\mathbf{2}}$ & 188 & 4,90 & 20,40 & 12,9835 & 2,89527 & $-0,255$ & $-0,012$ \\
$\boldsymbol{g}_{\mathbf{3}}$ & 188 & 1,40 & 13,40 & 8,3702 & 3,09861 & $-0,298$ & $-1,001$ \\
$\boldsymbol{g}_{\mathbf{4}}$ & 188 & 587 & 129916 & 17313,84 & 19069,325 & 2,194 & 2,011 \\
\hline
\end{tabular}


İGİ ve dört değerlerlendirme kriterine ilişkin çarpıklık ve basılılk değerlerine bakıldığında, kişi başına düşen GSMG dışındaki bütün değerlerin normal dağ $11 \mathrm{~m}$ göstermiş olduğu belirlenmiştir. İGİ ve değerlendirme kriterleri arasında bir ilişki olup olmadığını belirlemek için korelasyon değerlerine bakılmıştır. Tablo 3'te tüm değişkenler arasındaki korelasyon değerleri verilmiştir.

Tablo 3. Korelasyon Matrisi

\begin{tabular}{|c|c|c|c|c|c|}
\hline & İGI & $g_{1}$ & $g_{2}$ & $g_{3}$ & $g_{4}$ \\
\hline İGİ & 1 & & & & \\
\hline$g_{1}$ & $0,902 * *$ & 1 & & & \\
\hline$g_{2}$ & $0,918^{* *}$ & $0,801 * *$ & 1 & & \\
\hline$g_{3}$ & $0,908^{* *}$ & $0,749^{* *}$ & $0,831^{* *}$ & 1 & \\
\hline$g_{4}$ & $0,737 * *$ & $0,626^{* *}$ & $0,601^{* *}$ & $0,592^{* *}$ & 1 \\
\hline
\end{tabular}

** 0,01 düzeyinde anlamlıdır.

Tabloda verilen korelasyon katsayılarına bakıldığında, İGİ ve değerlendirme kriterleri arasında \%1 önem seviyesinde istatistiksel olarak anlamlı bir ilişki olduğu görülmektedir. Kişi başına düşen GSMG dışındaki değişkenler arasında 0,70 eşik değerinin üzerinde yüksek derecede korelasyon ilişkisi olduğu belirlenmiştir. Tüm değişkenler arasında hem tek yönlü hemde çift yönlü korelasyon ilişkisi olduğu tespit edilmiştir.

Analizde kullanılacak değerlendirme kriterleri ve bu kriterlere ait tanımlayıcı istatistikler verildikten sonra 188 adet alternatif ve 4 adet kriter için UTADIS uygulaması gerçekleştirilmiştir. UTADIS tekniği tarafindan hesaplanan sonuçlara bakıldığında, ülkeler gelişmiş̧lik düzeyleri açısından fayda skorlarına göre sinıflandırılmıştır. Tablo 4'e göre 188 ülkenin 84'ü çok yüksek $\left(C_{1}\right)$, tablo 5'e göre 47'si yüksek $\left(C_{2}\right)$, tablo 6'ya göre 30'u orta $\left(C_{3}\right)$ ve tablo 7'ye göre 27 'si ise düşük $\left(C_{4}\right)$ düzeyde gelişmişlik seviyesine sahip ülke kategorisinde sınıflandırılmıştır. Ayrıca, grupları ayıran eşik değerleri $0.150,0.254$ ve 0.354 olarak elde edilmiştir. Buna göre, 0-1 ölçeğinde global fayda skoru 0,150'den düşük olan alternatiflerin birinci grupta, global fayda skoru 0,150 ile 0,254 arasında yer alan alternatiflerin ikinci grupta, 0,254 ile 0,354 arasinda yer alan alternatiflerin üçüncü grupta ve son olarak global fayda skoru 0,354 'ten yüksek olan alternatiflerin dördüncü grupta yer almaları gerekmektedir. UTADIS uygulaması için belirlenmesi gereken parametrelerden olan alt aralık sayısı 4 olarak alınmıştır.

Tablo 4. UTADIS Tarafindan Sonuçların Sinıflandırılması (Çok Yüksek Insani Gelişmişlik Indeksine Sahip Ülkeler)

\begin{tabular}{|c|c|c|c|c|c|c|c|}
\hline \multirow[b]{2}{*}{$\begin{array}{l}\text { Sira } \\
\text { No: }\end{array}$} & \multirow[b]{2}{*}{ Ülkeler } & \multicolumn{2}{|c|}{ Gruplar } & \multirow[b]{2}{*}{$\begin{array}{l}\text { Fayda } \\
\text { Skoru }\end{array}$} & \multirow[b]{2}{*}{ İGİ Skoru } & \multirow[b]{2}{*}{$\begin{array}{l}\text { Ülke } \\
\text { Sayısı }\end{array}$} & \multirow[b]{2}{*}{ Eşikler } \\
\hline & & \begin{tabular}{|c|} 
UTADI \\
$\mathbf{S}$ \\
\end{tabular} & UNDP & & & & \\
\hline 1 & İsviçre & $\mathrm{C} 1$ & $\mathrm{C} 1$ & 0 & 1 & \multirow{3}{*}{84 Ülke } & 0,150 \\
\hline 2 & İngiltere & $\mathrm{C} 1$ & $\mathrm{C} 1$ & 0.00357 & 0.99643 & & 0,254 \\
\hline 3 & Avustralya & $\mathrm{C} 1$ & $\mathrm{C} 1$ & 0.00714 & 0.99286 & & 0.354 \\
\hline
\end{tabular}


Ülkelerin İnsani Gelişmişslik Sinıflamalarının UTADIS Yaklaşımı Aracılığıyla Yeniden Hesaplanması ve Değerlendirilmesi

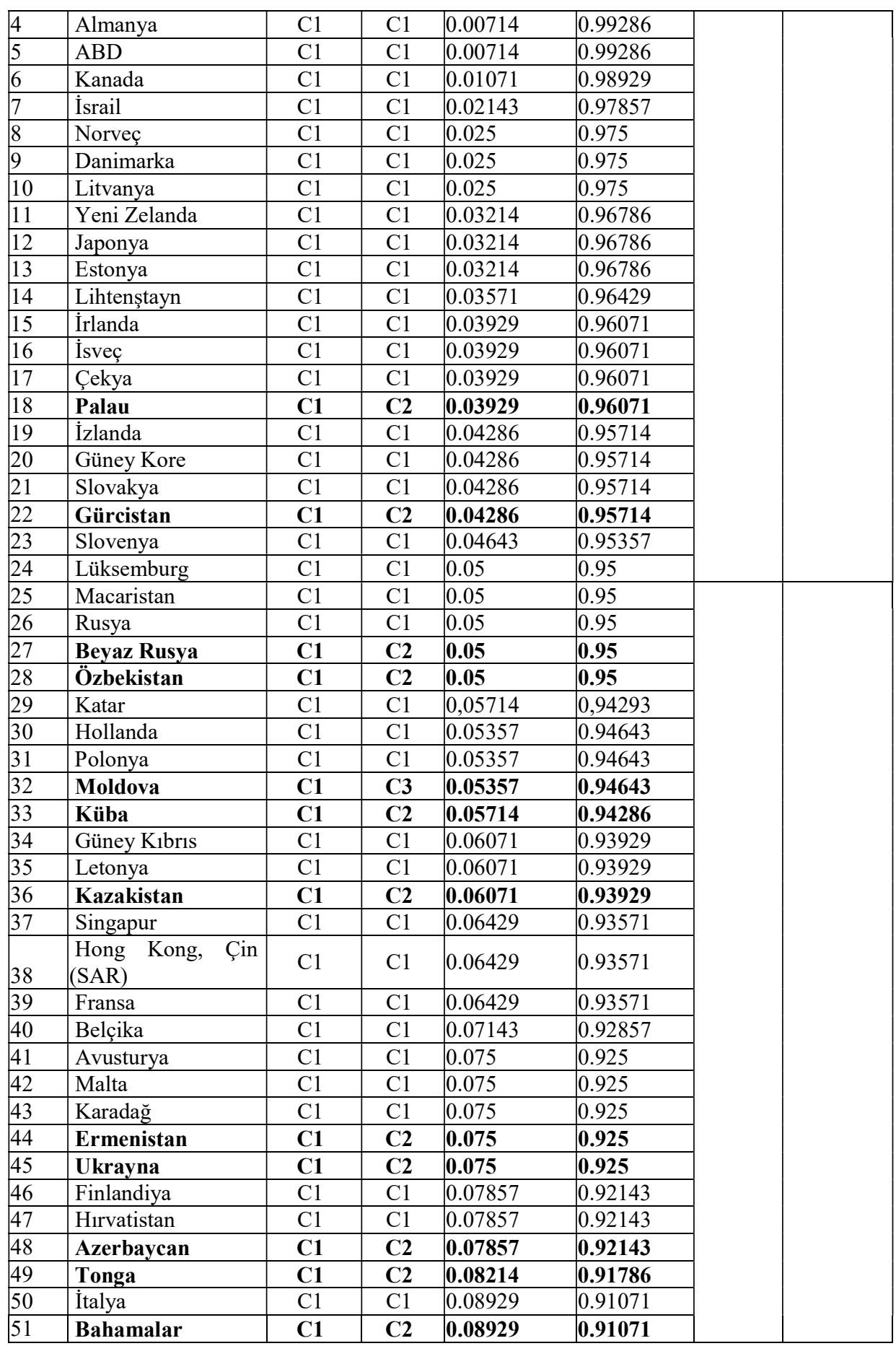




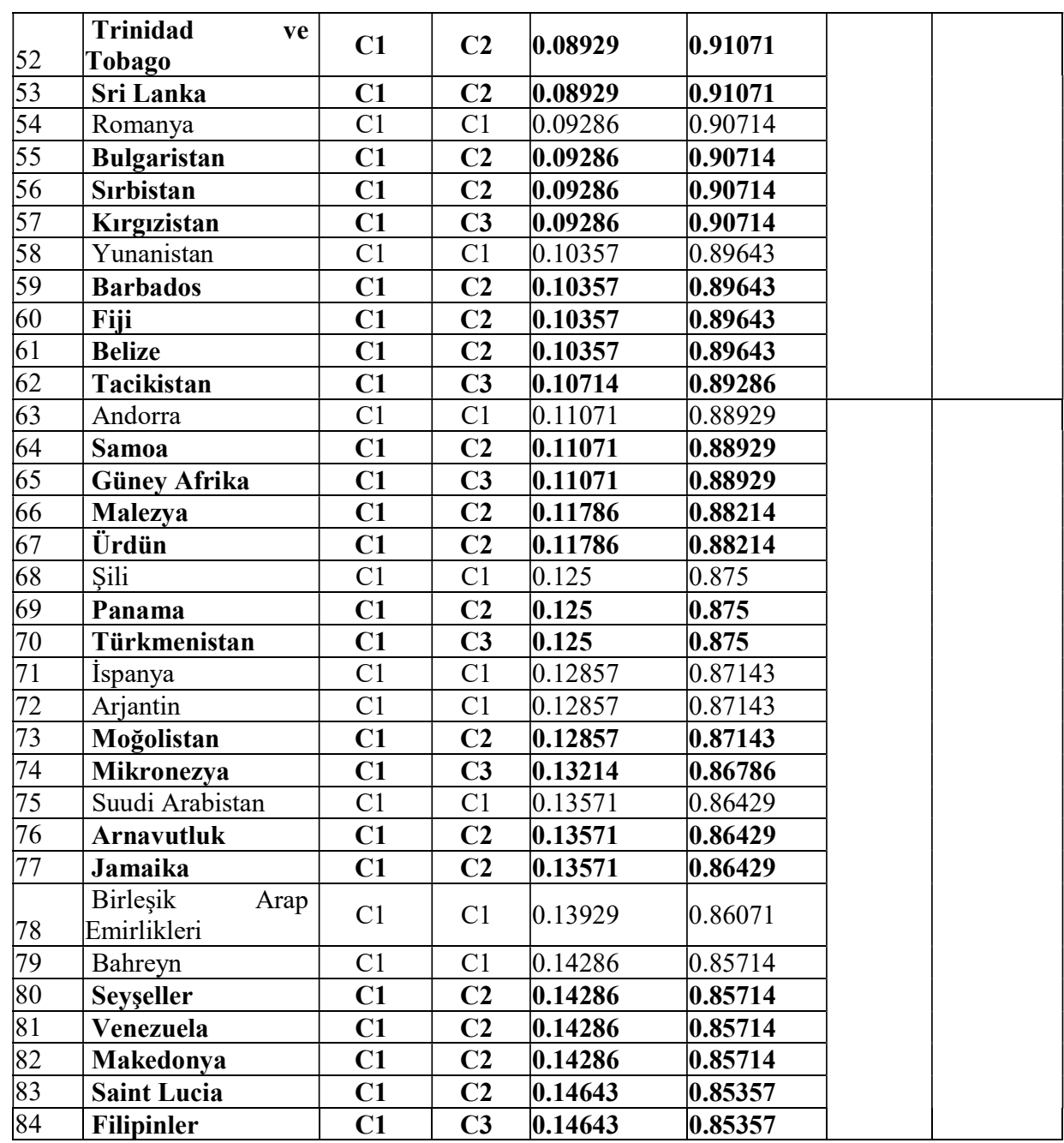

Tablo 4'e bakıldığında, UNDP tarafından yapılan gruplandırma işlemine göre $C_{1}$ grubunda 51 ülke yer alırken, UTADIS analizi sonucu bu grupta 84 ülke yer almıştır. UNDP'ye göre 29 ülkenin $C_{2}$ ve 7 ülkenin $C_{3}$ grubunda yer alması gerekirken, UTADIS tarafindan $C_{1}$ grubunda sinıflandırılmıştır. Bu ülkelerin global fayda skoruna göre $C_{1}$ grubunda yer almaları gerekmektedir. Dolayısıyla, $C_{1}$ grubunda, 3 adet alternatifin sınıflandırma hatasına maruz kaldığı ve farklı bir grupta sınıflandırıldığı tespit edilmiştir. 
Ülkelerin İnsani Geliş̧mişlik Sinıflamalarının UTADIS Yaklaşımı Aracılı̆̆gyla Yeniden Hesaplanması ve Değerlendirilmesi

Tablo 5. UTADIS Tarafindan Sonuçların Sinıflandırllması (Yüksek İnsani Gelişmişlik Indeksine Sahip Ülkeler)

\begin{tabular}{|c|c|c|c|c|c|c|c|}
\hline \multirow{2}{*}{$\begin{array}{l}\text { Sira } \\
\text { No: }\end{array}$} & \multirow{2}{*}{ Ülkeler } & \multicolumn{2}{|c|}{ Gruplar } & \multirow{2}{*}{ Fayda Skoru } & \multirow{2}{*}{ İGİ Skoru } & \multirow{2}{*}{$\begin{array}{c}\text { Ülke } \\
\text { Sayısı }\end{array}$} & \multirow{2}{*}{ Eşikler } \\
\hline & & UTADIS & UNDP & & & & \\
\hline 1 & Antigua ve Barbuda & $\mathrm{C} 2$ & $\mathrm{C} 2$ & 0.15 & 0.85 & \multirow{23}{*}{47 Ülke } & 0,150 \\
\hline 2 & Botsvana & $\mathrm{C2}$ & C3 & 0.15 & 0.85 & & 0,254 \\
\hline 3 & Mauritius & $\mathrm{C} 2$ & $\mathrm{C} 2$ & 0.15357 & 0.84643 & & 0.354 \\
\hline 4 & Brunei Darussalam & $\mathrm{C2}$ & C1 & 0.15714 & 0.84286 & & \\
\hline 5 & Bosna Hersek & $\mathrm{C} 2$ & $\mathrm{C} 2$ & 0.15714 & 0.84286 & & \\
\hline 6 & Peru & $\mathrm{C} 2$ & $\mathrm{C} 2$ & 0.15714 & 0.84286 & & \\
\hline 7 & Portekiz & $\mathrm{C2}$ & C1 & 0.16071 & 0.83929 & & \\
\hline 8 & Filistin & $\mathrm{C2}$ & $\mathbf{C 3}$ & 0.16071 & 0.83929 & & \\
\hline 9 & İran & $\mathrm{C} 2$ & $\mathrm{C} 2$ & 0.16429 & 0.83571 & & \\
\hline 10 & Kosta Rika & $\mathrm{C} 2$ & $\mathrm{C} 2$ & 0.16786 & 0.83214 & & \\
\hline 11 & Uruguay & $\mathrm{C} 2$ & $\mathrm{C} 2$ & 0.17143 & 0.82857 & & \\
\hline 12 & Lübnan & $\mathrm{C} 2$ & $\mathrm{C} 2$ & 0.17143 & 0.82857 & & \\
\hline 13 & Meksika & $\mathrm{C} 2$ & $\mathrm{C} 2$ & 0.17143 & 0.82857 & & \\
\hline 14 & Grenada & $\mathrm{C} 2$ & $\mathrm{C} 2$ & 0.17143 & 0.82857 & & \\
\hline 15 & $\begin{array}{l}\text { Saint Vincent ve } \\
\text { Grenadinler }\end{array}$ & $\mathrm{C} 2$ & $\mathrm{C} 2$ & 0.17143 & 0.82857 & & \\
\hline 16 & Saint Kitts ve Nevis & $\mathrm{C} 2$ & $\mathrm{C} 2$ & 0.17857 & 0.82143 & & \\
\hline 17 & Guyana & $\mathrm{C2}$ & C3 & 0.17857 & 0.82143 & & \\
\hline 18 & Ekvador & $\mathrm{C} 2$ & $\mathrm{C} 2$ & 0.18214 & 0.81786 & & \\
\hline 19 & Surinam & $\mathrm{C} 2$ & $\mathrm{C} 2$ & 0.18214 & 0.81786 & & \\
\hline 20 & Bolivya & $\mathrm{C2}$ & $\mathbf{C 3}$ & 0.18571 & 0.81429 & & \\
\hline 21 & Umman & $\mathrm{C} 2$ & $\mathrm{C} 2$ & 0.18929 & 0.81071 & & \\
\hline 22 & Gabon & $\mathrm{C2}$ & C3 & 0.18929 & 0.81071 & & \\
\hline 23 & Paraguay & $\mathrm{C2}$ & C3 & 0.18929 & 0.81071 & & \\
\hline 24 & Vietnam & $\mathrm{C2}$ & C3 & 0.19286 & 0.80714 & & \\
\hline 25 & Türkiye & $\mathrm{C} 2$ & $\mathrm{C} 2$ & 0.19643 & 0.80357 & & \\
\hline 26 & Tayland & $\mathrm{C} 2$ & $\mathrm{C} 2$ & 0.19643 & 0.80357 & & \\
\hline 27 & Dominika & $\mathrm{C} 2$ & $\mathrm{C} 2$ & 0.19643 & 0.80357 & & \\
\hline 28 & Endonezya & $\mathrm{C2}$ & C3 & 0.19643 & 0.80357 & & \\
\hline 29 & Brezilya & $\mathrm{C} 2$ & $\mathrm{C} 2$ & 0.2 & 0.8 & & \\
\hline 30 & Cezayir & $\mathrm{C} 2$ & $\mathrm{C} 2$ & 0.2 & 0.8 & & \\
\hline 31 & Kiribati & $\mathrm{C2}$ & C3 & 0.2 & 0.8 & & \\
\hline 32 & $\begin{array}{l}\text { Dominik } \\
\text { Cumhuriyeti }\end{array}$ & $\mathrm{C} 2$ & $\mathrm{C} 2$ & 0.20357 & 0.79643 & & \\
\hline 33 & Zimbabve & $\mathrm{C2}$ & C4 & 0.20357 & 0.79643 & & \\
\hline 34 & Çin & $\mathrm{C} 2$ & $\mathrm{C} 2$ & 0.20714 & 0.79286 & & \\
\hline 35 & Kolombiya & $\mathrm{C} 2$ & $\mathrm{C} 2$ & 0.20714 & 0.79286 & & \\
\hline 36 & Kuveyt & $\mathrm{C2}$ & C1 & 0.21786 & 0.78214 & & \\
\hline 37 & Libya & $\mathrm{C} 2$ & $\mathrm{C} 2$ & 0.21786 & 0.78214 & & \\
\hline 38 & Tunus & $\mathrm{C} 2$ & $\mathrm{C} 2$ & 0.225 & 0.775 & & \\
\hline 39 & Misır & $\mathrm{C2}$ & C3 & 0.225 & 0.775 & & \\
\hline 40 & Gana & $\mathrm{C2}$ & C3 & 0.23214 & 0.76786 & & \\
\hline 41 & Zambiya & $\mathrm{C2}$ & C3 & 0.23214 & 0.76786 & & \\
\hline 42 & Vanuatu & $\mathrm{C2}$ & C3 & 0.23571 & 0.76429 & & \\
\hline 43 & Svaziland & $\mathrm{C2}$ & $\mathrm{C4}$ & 0.23571 & 0.76429 & & \\
\hline
\end{tabular}




\begin{tabular}{|l|l|l|l|l|l|l|l|}
\hline 44 & Namibya & C2 & C3 & $\mathbf{0 . 2 3 9 2 9}$ & $\mathbf{0 . 7 6 0 7 1}$ & & \\
\hline 45 & Irak & C2 & C3 & $\mathbf{0 . 2 4 2 8 6}$ & $\mathbf{0 . 7 5 7 1 4}$ & & \\
\hline 46 & EI Salvador & C2 & C3 & $\mathbf{0 . 2 4 6 4 3}$ & $\mathbf{0 . 7 5 3 5 7}$ & & \\
\hline 47 & Nikaragua & C2 & C3 & $\mathbf{0 . 2 4 6 4 3}$ & $\mathbf{0 . 7 5 3 5 7}$ & & \\
\hline
\end{tabular}

Tablo 5'e bakıldığında, UNDP tarafından yapılan gruplandırma işlemine göre $C_{2}$ grubunda 55 ülke yer alırken, UTADIS analizi sonucu bu grupta 47 ülke yer almıştır. UNDP'ye göre 3 ülkenin $C_{1}, 17$ ülkenin $C_{3}$ ve 2 ülkenin $C_{4}$ grubunda yer alması gerekirken, UTADIS tarafindan $C_{2}$ grubunda sınıflandırılmıştır. $\mathrm{Bu}$ ülkelerin global fayda skoruna göre $C_{2}$ grubunda yer almaları gerekmektedir. Dolayısıyla, $C_{2}$ grubunda, 30 adet alternatifin siniflandirma hatasina maruz kaldığı ve farklı bir grupta sinıflandırıldığı tespit edilmiştir.

Tablo 6. UTADIS Tarafindan Sonuçların Sinıflandırılması (Orta Düzeyde İnsani Gelişmişlik İndeksine Sahip Ülkeler)

\begin{tabular}{|c|c|c|c|c|c|c|c|}
\hline \multirow[b]{2}{*}{$\begin{array}{l}\text { Sira } \\
\text { No: }\end{array}$} & \multirow[b]{2}{*}{ Ülkeler } & \multicolumn{2}{|c|}{ Gruplar } & \multirow[b]{2}{*}{ Fayda Skoru } & \multirow[b]{2}{*}{ İGİ Skoru } & \multirow{2}{*}{$\begin{array}{c}\text { Ülke } \\
\text { Sayısı }\end{array}$} & \multirow[b]{2}{*}{ Eşikler } \\
\hline & & $\begin{array}{c}\text { UTADI } \\
\mathbf{S}\end{array}$ & UNDP & & & & \\
\hline 1 & Guatemala & C3 & C3 & 0.25357 & 0.74643 & \multirow{30}{*}{30 Ülke } & 0,150 \\
\hline 2 & Hindistan & C3 & C3 & 0.25357 & 0.74643 & & 0,254 \\
\hline 3 & Kongo & C3 & C3 & 0.25357 & 0.74643 & & 0.354 \\
\hline 4 & Kenya & C3 & $\mathrm{C} 3$ & 0.25357 & 0.74643 & & \\
\hline 5 & Maldivler & C3 & $\mathrm{C2}$ & 0.25714 & 0.74286 & & \\
\hline 6 & Honduras & C3 & C3 & 0.25714 & 0.74286 & & \\
\hline 7 & Kamerun & C3 & $\mathrm{C4}$ & 0.26071 & 0.73929 & & \\
\hline 8 & Madagaskar & $\mathbf{C 3}$ & $\mathbf{C 4}$ & 0.26071 & 0.73929 & & \\
\hline 9 & Lesotho & C3 & $\mathrm{C4}$ & 0.26071 & 0.73929 & & \\
\hline 10 & $\begin{array}{l}\text { Demokratik Kongo } \\
\text { Cumhuriyeti }\end{array}$ & C3 & C4 & 0.26071 & 0.73929 & & \\
\hline 11 & Nijerya & C3 & $\mathrm{C4}$ & 0.26429 & 0.73571 & & \\
\hline 12 & Tanzanya & C3 & $\mathbf{C 4}$ & 0.27143 & 0.72857 & & \\
\hline 13 & Uganda & $\mathrm{C3}$ & $\mathrm{C4}$ & 0.275 & 0.725 & & \\
\hline 14 & Ekvator Ginesi & $\mathrm{C} 3$ & $\mathrm{C} 3$ & 0.28214 & 0.71786 & & \\
\hline 15 & \begin{tabular}{|ll} 
Sao Tome & ve \\
Principe & \\
\end{tabular} & C3 & $\mathrm{C} 3$ & 0.2925 & 0.7075 & & \\
\hline 16 & Solomon Adaları & $\mathbf{C 3}$ & $\mathrm{C4}$ & 0.2925 & 0.7075 & & \\
\hline 17 & Laos & C3 & C3 & 0.29929 & 0.70071 & & \\
\hline 18 & Bangladeş & $\mathrm{C} 3$ & $\mathrm{C} 3$ & 0.29929 & 0.70071 & & \\
\hline 19 & Haiti & $\mathbf{C 3}$ & $\mathbf{C 4}$ & 0.29929 & 0.70071 & & \\
\hline 20 & Pakistan & $\mathrm{C} 3$ & $\mathrm{C} 3$ & 0.30607 & 0.69393 & & \\
\hline 21 & \begin{tabular}{|l|} 
Suriye \\
\end{tabular} & $\mathrm{C3}$ & C4 & 0.30607 & 0.69393 & & \\
\hline 22 & Fas & $\mathrm{C} 3$ & $\mathrm{C} 3$ & 0.31286 & 0.68714 & & \\
\hline 23 & Angora & $\mathbf{C 3}$ & $\mathrm{C4}$ & 0.31286 & 0.68714 & & \\
\hline 24 & Fildişi Sahili & C3 & $\mathrm{C4}$ & 0.31286 & 0.68714 & & \\
\hline 25 & Cabo Verde & $\mathrm{C} 3$ & $\mathrm{C} 3$ & 0.32643 & 0.67357 & & \\
\hline 26 & Komorlar & C3 & C4 & 0.32643 & 0.67357 & & \\
\hline 27 & Güney Sudan & C3 & C4 & 0.32643 & 0.67357 & & \\
\hline 28 & Kamboçya & $\mathrm{C} 3$ & $\mathrm{C} 3$ & 0.33321 & 0.66679 & & \\
\hline 29 & Myanmar & $\mathrm{C} 3$ & $\mathrm{C} 3$ & 0.33321 & 0.66679 & & \\
\hline 30 & Togo & C3 & C4 & 0.33321 & 0.66679 & & \\
\hline
\end{tabular}


Ülkelerin İnsani Geliş̧mişlik Sinıflamalarının UTADIS Yaklaşımı Aracıllğıyla Yeniden Hesaplanması ve Değerlendirilmesi

Tablo 6'ya bakıldığında, UNDP tarafından yapılan gruplandırma işlemine göre $C_{3}$ grubunda 41 ülke yer alırken, UTADIS analizi sonucu bu grupta 30 ülke yer almıştır. UNDP'ye göre 1 ülkenin $C_{2}$ ve 15 ülkenin $C_{4}$ grubunda yer alması gerekirken, UTADIS tarafından $C_{3}$ grubunda sınıflandırılmıştır. Bu ülkelerin global fayda skoruna göre $C_{3}$ grubunda yer almaları gerekmektedir. Dolayısıyla, $C_{3}$ grubunda, 27 adet alternatifin sinıflandırma hatasına maruz kaldığı ve farklı bir grupta sınıflandırıldığ tespit edilmiştir.

Tablo 7. UTADIS Tarafından Sonuçların Sınıflandırılması (Düşük İnsani Gelişmişlik İndeksine Sahip Ülkeler)

\begin{tabular}{|c|c|c|c|c|c|c|c|}
\hline \multirow{2}{*}{$\begin{array}{l}\text { Sira } \\
\text { No: }\end{array}$} & \multirow{2}{*}{ Ülkeler } & \multicolumn{2}{|c|}{ Gruplar } & \multirow{2}{*}{ Fayda Skoru } & \multirow{2}{*}{ İGİ Skoru } & \multirow{2}{*}{$\begin{array}{c}\text { Ülke } \\
\text { Sayısı }\end{array}$} & \multirow{2}{*}{ Eşikler } \\
\hline & & UTADIS & UNDP & & & & \\
\hline 1 & Timor-Leste & $\mathrm{C4}$ & $\mathbf{C 3}$ & 0.35357 & 0.64643 & & 0,150 \\
\hline 2 & Malawi & $\mathrm{C} 4$ & $\mathrm{C} 4$ & 0.35357 & 0.64643 & & 0,254 \\
\hline 3 & Liberya & $\mathrm{C} 4$ & $\mathrm{C} 4$ & 0.35357 & 0.64643 & & 0.354 \\
\hline 4 & $\begin{array}{ll}\text { Papua } & \text { Yeni } \\
\text { Gine } & \end{array}$ & $\mathrm{C} 4$ & $\mathrm{C} 4$ & 0.36036 & 0.63964 & & \\
\hline 5 & Moritanya & $\mathrm{C} 4$ & $\mathrm{C} 4$ & 0.36036 & 0.63964 & & \\
\hline 6 & $\begin{array}{l}\text { Orta Afrika } \\
\text { Cumhuriyeti }\end{array}$ & $\mathrm{C} 4$ & $\mathrm{C} 4$ & 0.36714 & 0.63286 & & \\
\hline 7 & Nepal & $\mathrm{C4}$ & $\mathbf{C 3}$ & 0.37393 & 0.62607 & & \\
\hline 8 & Cibuti & $\mathrm{C} 4$ & $\mathrm{C} 4$ & 0.37393 & 0.62607 & & \\
\hline 9 & Eritre & $\mathrm{C} 4$ & $\mathrm{C} 4$ & 0.3875 & 0.6125 & & \\
\hline 10 & Ruanda & $\mathrm{C} 4$ & $\mathrm{C} 4$ & 0.39429 & 0.60571 & & \\
\hline 11 & Sudan & $\mathrm{C} 4$ & $\mathrm{C} 4$ & 0.41464 & 0.58536 & & \\
\hline 12 & Benin & $\mathrm{C} 4$ & $\mathrm{C} 4$ & 0.41464 & 0.58536 & & \\
\hline 13 & Afganistan & $\mathrm{C} 4$ & $\mathrm{C} 4$ & 0.41464 & 0.58536 & 27 Ülke & \\
\hline 14 & Mozambik & $\mathrm{C} 4$ & $\mathrm{C} 4$ & 0.41464 & 0.58536 & & \\
\hline 15 & Gambiya & $\mathrm{C} 4$ & $\mathrm{C} 4$ & 0.42821 & 0.57179 & & \\
\hline 16 & Sierra Leone & $\mathrm{C} 4$ & $\mathrm{C} 4$ & 0.42821 & 0.57179 & & \\
\hline 17 & Butan & C4 & C3 & 0.44179 & 0.55821 & & \\
\hline 18 & Yemen & $\mathrm{C} 4$ & $\mathrm{C} 4$ & 0.44857 & 0.55143 & & \\
\hline 19 & Burundi & $\mathrm{C} 4$ & $\mathrm{C} 4$ & 0.44857 & 0.55143 & & \\
\hline 20 & Gine-Bissau & $\mathrm{C} 4$ & $\mathrm{C} 4$ & 0.45536 & 0.54464 & & \\
\hline 21 & Senegal & $\mathrm{C} 4$ & $\mathrm{C} 4$ & 0.46214 & 0.53786 & & \\
\hline 22 & Etiyopya & $\mathrm{C} 4$ & $\mathrm{C} 4$ & 0.47571 & 0.52429 & & \\
\hline 23 & Gine & $\mathrm{C} 4$ & $\mathrm{C} 4$ & 0.47571 & 0.52429 & & \\
\hline 24 & Mali & $\mathrm{C} 4$ & $\mathrm{C} 4$ & 0.49607 & 0.50393 & & \\
\hline 25 & Çad & $\mathrm{C} 4$ & $\mathrm{C} 4$ & 0.49607 & 0.50393 & & \\
\hline 26 & Nijer & $\mathrm{C} 4$ & $\mathrm{C} 4$ & 0.53679 & 0.46321 & & \\
\hline 27 & Burkina Faso & $\mathrm{C} 4$ & $\mathrm{C} 4$ & 0.55714 & 0.44286 & & \\
\hline
\end{tabular}

Tablo 7'ye bakıldığında, UNDP tarafından yapılan gruplandırma işlemine göre $C_{4}$ grubunda 41 ülke yer alırken, UTADIS analizi sonucu bu grupta 27 ülke yer almıştır. UNDP'ye göre 3 ülkenin $C_{3}$ grubunda yer alması gerekirken, UTADIS tarafindan $C_{4}$ grubunda sinıflandırılmıştır. Bu ülkelerin global fayda skoruna göre $C_{4}$ grubunda yer almaları gerekmektedir. Dolayısıyla, $C_{4}$ grubunda, 
17 adet alternatifin sınıflandırma hatasına maruz kaldığı ve farklı bir grupta sinıflandırıldığı tespit edilmiştir.

Tablo 8'de UTADIS tarafindan hesaplanan değerlendirme kriterlerinin ağırlıkları verilmiştir. Tablo 8'de yer alan kriter ağırlıklarına bakıldığında, marjinal faydalara göre en önemli kriter \%27,16 ile $g_{4}$ kriteridir. Sirasıyla, $g_{3}$ kriteri \%24,58 ile ikinci, $g_{2}$ kriteri \%24,03 ile üçüncü sırada yer almaktadır. Son olarak, en az ağırlığa sahip kriter ise $\% 23,87$ ile $g_{1}$ kriteridir.

Tablo 8. Değerlendirme Kriterlerinin Ă̆ırlıklart

\begin{tabular}{c|c}
\hline Değerlendirme Kriterleri & Kriter A ğırlığ $\mathbf{I}$ \\
\hline $\boldsymbol{g}_{\mathbf{1}}$ & $23,87 \%$ \\
$\boldsymbol{g}_{\mathbf{2}}$ & $24,03 \%$ \\
$\boldsymbol{g}_{\mathbf{3}}$ & $24,58 \%$ \\
$\boldsymbol{g}_{\mathbf{4}}$ & $27,16 \%$ \\
\hline
\end{tabular}

Uygulamada, analizde kullanılan kriterlerin marjinal ağırlıkları da elde edilerek yorumlanmaktadır. Modelin kurularak çözüldüğü sayfadan, kriter ağırlıklarının marjinal değerleri ile alt aralıklar için belirlenen kesim noktası değerleri alınarak, kriterlerin marjinal ağırlıklarının grafik gösterimi çıkarılmıştır. Dört kriter için marjinal kriter ağırlığı grafikleri Şekil 4'teki gibi elde edilmiştir.

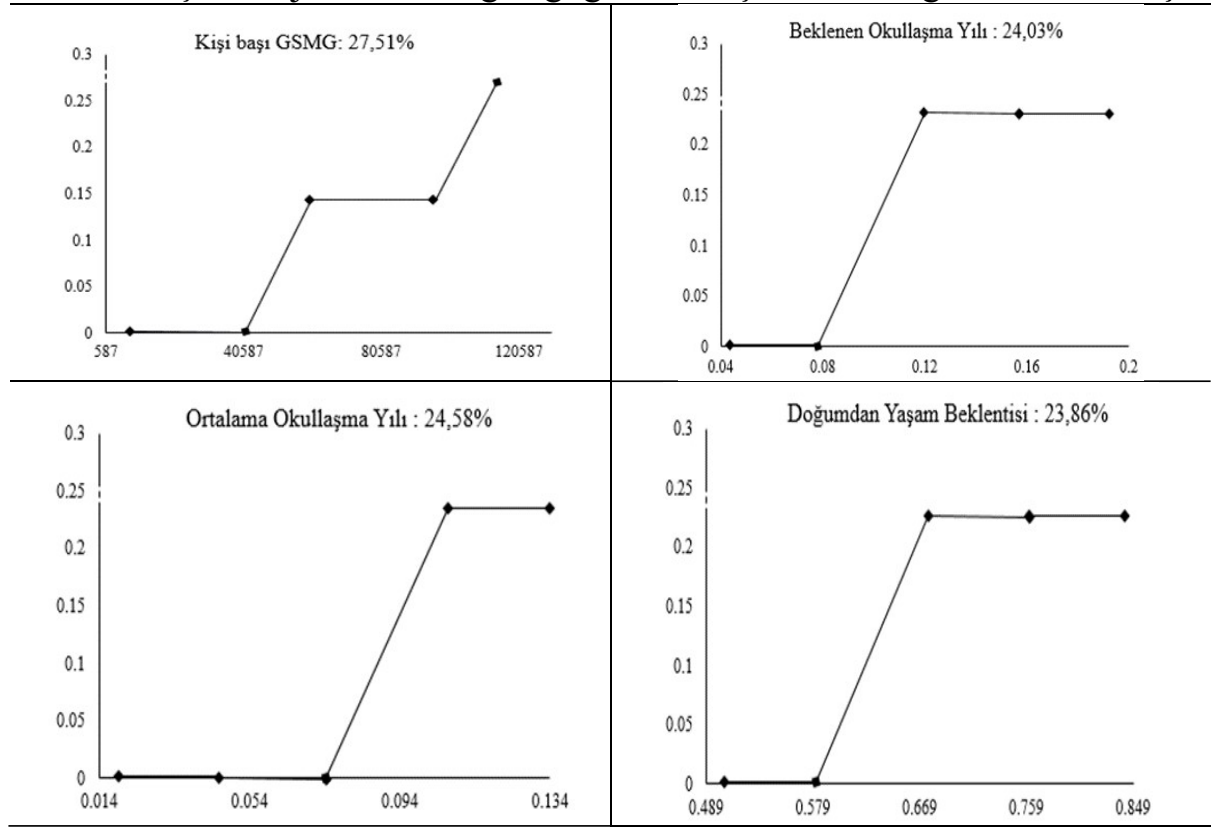

Şekil 4. UTADIS Uygulamasında Yer Alan Krtierlerin Marjinal Faydası

Şekil 4'e bakıldığında önem ağırlığı 0'dan farklı olan kriterler için marjinal ağırlıkları gösteren grafikler görülmektedir. Grafiklerin yatay eksenleri, ilk durumda analizde belirlenen alt aralıkların kesim noktalarını ifade etmektedir. 
Ülkelerin İnsani Geliş̧mişlik Sinıflamalarının UTADIS Yaklaşımı Aracılı̆̆gyla Yeniden Hesaplanması ve Değerlendirilmesi

Dikey eksenlerde ise önem ağırlıkları yer almaktadır. Grafiklerin yorumları aşağıdaki gibidir.

Kişi başına düşen milli gelir kriteri için 40.587 ile 80.587 aralığında yer alan alternatifler bu kriterin \%15'lik kısmını etkilemektedir. \%27,51'lik ağıllık ise kişi başına düşen milli gelir değeri ${ }^{80.587}$ 'den büyük alternatiflerin etkisini oluşturmaktadır. Beklenen okullaşma yılı kriterine bakıldığında, kriter değeri 0,12'den büyük İGİ değerine sahip ülkeler, bu kriterin önem ağırlığının \%24,03 olmasını sağlamaktadır. Ortalama okullaşma yılı kriterine bakıldığında, kriter değeri 0,094'ten büyük İGİ değerine sahip ülkeler, bu kriterin önem ağırlığının $\% 24,58$ olmasını sağlamaktadır. Son olarak, doğumda yaşam beklentisi kriterine bakıldığında, kriter değeri 0,669 'dan büyük İGİ değerine sahip ülkeler, bu kriterin önem ağırlı̆̆ının \%23,86 olmasını sağlamaktadır.

Bir sonraki adım UTADIS modelinin tahmin gücünün hesaplanmasıdır. Tahmin gücünün hesaplanması için öncelikle modelin tahmin hatasının hesaplanması gerekmektedir. Fazla tahmin hatas $\sigma^{+}(a)$ ve eksik tahmin hatas $\sigma^{-}(a)$ olmak üzere iki tip hata vardır. UTADIS'te fazla tahmin hatası birinci tip hatayı, eksik tahmin hatası ise ikinci tip hatayı ifade etmektedir. Birinci ve ikinci tip hatanın toplamı modelin toplam hatasına eşittir. UTADIS modelinin hata yüzdeleri Tablo 9'da verilmiştir.

Tablo 9. UTADIS Modelinin Hata Yüzdeleri

\begin{tabular}{c|c}
\hline & Hata Yüzdesi \\
\hline Birinci Tip Hata & $\% 37,3$ \\
İkinci Tip Hata & $\% 3,7$ \\
\hline Toplam & $\% 41$ \\
\hline
\end{tabular}

Bu uygulamada 188 adet alternatiften 70 tanesi fazla tahmin hatasi ile 7 tanesi de eksik tahmin hatası ile sınıflandırılmıştır. Modelin toplam hatası \%41 oranındadır. Bu durumda, uygulanan UTADIS modelinin tahmin gücünün $\% 59$ oranında olduğu söylenebilir. UTADIS modelinin tahmin gücü Tablo 10 'da verilmiştir.

Tablo 10. UTADIS Modelinin Tahmin Gücü

\begin{tabular}{ccccc}
\hline Gruplar & Grup Toplamı & Model & $\begin{array}{c}\text { Farklı } \\
\text { Sinıflandırma }\end{array}$ & $\begin{array}{c}\text { Tahmin } \\
\text { Gücü }\end{array}$ \\
\hline $\boldsymbol{C}_{\mathbf{1}}$ & 51 & 48 & 3 & $\% 94,12$ \\
$\boldsymbol{C}_{\mathbf{2}}$ & 55 & 25 & 30 & $\% 45,45$ \\
$\boldsymbol{C}_{\mathbf{3}}$ & 41 & 14 & 27 & $\% 34,15$ \\
$\boldsymbol{C}_{\mathbf{4}}$ & 41 & 24 & 17 & $\% 58,54$ \\
\hline Toplam & 188 & 111 & 77 & \\
\hline
\end{tabular}

Kurulan UTADIS modelinin tahmin gücüne göre siniflandırma yapıldığında, çok yüksek İGİ değerine sahip ülkelerin 3'ü, yüksek İGİ değerine sahip ülkelerin 30'u, orta düzeyde İGİ değerine sahip ülkelerin 27'si ve düşük İGI değerine sahip ülkelerin ise 17'si model tarafindan UNDP'den farklı bir 
grupta sınıflandırılmıştır. Uygulanan UTADIS modeli ile 188 alternatifin 111 'i UNDP'nin yaptı̆ğ gruplama ile aynı sinıflandırılırken, 77'si farklı bir grupta sınıflandırılmıştır.

\section{Sonuç ve Değerlendirme}

Merkezine insanı yerleştiren ve insan yaşamının en temel unsurları olan sağlık, eğitim ve gelir ile ilgili göstergelerin biraraya gelmesiyle oluşturulan İGİ, insanlar için kaliteli yaşam standartlarını belirlemek amacıyla kullanılan en uygun ölçek olarak kabul edilmektedir. Bu çalışmada, 188 ülkenin İGİ verilerine göre çok kriterli bir sınıflandırma tekniği olan UTADIS ile yeniden sınıflandırılması yapılmıştır. UTADIS, alternatifleri minimum sinıflandırma hatası ile orijinal sinıflarına atayan bir sınıflandırma modelidir.

UNDP tarafından yapılan gruplandırma işlemine göre; birinci grupta yani çok yüksek gelişmişlik düzeyine sahip ülke kategorisinde $\left(C_{1}\right)$ 51, ikinci grupta yani yüksek gelişmişlik düzeyine sahip ülke kategorisinde $\left(C_{2}\right) 55$, üçüncü grupta yani orta gelişmişlik düzeyine sahip ülke kategorisinde $\left(C_{3}\right) 41$ ve dördüncü grupta yani düşük gelişmişlik düzeyine sahip ülke kategorisinde $\left(C_{4}\right) 41$ adet ülke bulunmaktadır.

Yapılan UTADIS analizi sonucu, ülkeler gelişmişlik düzeyleri açısından fayda skorlarına göre yeniden sınıflandırılmıştır. 188 ülkenin 84'ü çok yüksek $\left(C_{1}\right), 47$ ' si yüksek $\left(C_{2}\right), 30$ 'u orta $\left(C_{3}\right)$ ve 27 'si ise düşük $\left(C_{4}\right)$ düzeyde gelişmişlik seviyesine sahip ülke kategorisinde yer almıştır. UNDP, İGI'yi oluşturan tüm kriterlerin ağırlığını eşit kabul etmektedir. Aslında gerçek hayatta bu eşitlik söz konusu değildir. Ağırlıkların değişimi ülkelerin sınıflarını da değiştirmektedir. UTADIS yöntemi, bu değişikliğe izin vermektedir. Sonuç olarak, böyle bir sınıflandırma yapmak için kriterlerin bağımsız değerlendirilmesi ve farklı ağırlıkları dikkate alabilen ÇKKV sıralı sınıflandırma yöntemlerinden biri olan UTADIS yönteminin kullanılmasını önermekteyiz.

UTADIS modelinin toplam hatas1 \%41 ve dolayısıyla tahmin gücü $\% 59$ oranındadır. Uygulanan UTADIS modeli ile 188 alternatifin 111'i UNDP'nin bu ülkeleri atadığ 1 grup ile aynı sinıflandırılırken, 77'si farklı bir grupta sınıflandırılmıştır. UTADIS analizi sonuçlarına göre birçok ülkenin sınıfının değişmesi gerektiği gözlemlenmiştir.

\section{Kaynaklar}

Aguña, C. G., Kovacevic, M. (2010). Uncertainty and Sensitivity Analysis of the Human Development Index Human Development Research Paper (Vol. 47).

Altaş, D., Arikan, G. (2015). "The Analysis of Human Development Index with Cluster Analysis Techniques”. Social Sciences Research Journal, 6 (3), 126-138. 
Ülkelerin İnsani Geliş̧mişlik Sinıflamalarının UTADIS Yaklaşımı Aracıllğıyla Yeniden Hesaplanması ve Değerlendirilmesi

Bagolin, I., Comim, F. (2008). "Human Development Index (HDI) and its Family of Indexes: An Evolving Critical Review". Revista de Economia, 34 (2), 7 28.

Balla, V., Gaganis, C., Pasiouras, F., Zopounidis, C. (2014). "Multicriteria Decision Aid Models for the Prediction of Securities Class Actions: Evidence from the Banking Sector". OR spectrum, 36 (1), 57-72. doi: 10.1007/s00291-013-0333-8

Çolak, M., Ulucan, A. (2012). "Mobilya Endüstrisinde Kârlılı̆̆g Etkileyen Faktörlerin UTADIS Yaklaşımı ile Belirlenmesi”. Sosyoekonomi, 17 (17), 249-262.

Demir, S. (2006). Birleşmiş Milletler Kalkınma Programı İnsani Gelişme Endeksi ve Türkiye Açısından Değerlendirme. Ankara: DPT.

Devaud, J., Groussaud, G., Jacquet-Lagreze, E. (1980). "UTADIS: Une méthode de construction de fonctions d'utilité additives rendant compte de jugements globaux". European Working Group on Multicriteria Decision Aid, 94.

Diakoulaki, D., Zopounidis, C., Mavrotas, G., Doumpos, M. (1999). “The Use of a Preference Disaggregation Method in Energy Analysis and Policy Making”. Energy, 24 (2), 157-166. doi: 10.1016/S0360-5442(98)00081-4

Dimitras, A. (2001). Multicriteria Evaluation of Greek Construction Companies' Securities. Working Paper Series.

do Carvalhal Monteiro, R. L., Pereira, V., Costa, H. G. (2018). “A Multicriteria Approach to the Human Development Index Classification". Social Indicators Research, 136 (2), 417-438.

Doumpos, M., Zopounidis, C. (2002). "Business Failure Prediction: A Comparison of Classification Methods". Operational Research, 2 (3), 303319. doi: 10.1007/BF02936387

Duman, A. (2010). Multiple Criteria Sorting Methods Based on Support Vector Machines. (Yüksek Lisans Tezi).Ankara: The Graduate School of Natural and Applied Sciences of Middle East Technical University.

Gaganis, C., Pasiouras, F., Zopounidis, C. (2006). "External Auditors' Decisions in Eu Credit Institutions: A Multicriteria Approach". International Journal of Auditing, 10 (2), 163-182. doi: 10.1111/j.1099-1123.2006.00348.x

Herrero, C., Martínez, R., Villar, A. (2012). "A Newer Human Development Index". Journal of Human Development and Capabilities, 13 (2), 247-268.

Hou, J., Walsh, P. P., Zhang, J. (2015). "The Dynamics of Human Development Index". The Social Science Journal, 52 (3), 331-347. doi: 0.1016/j.soscij.2014.07.003

Karabulut, T., Kaya, N., Gürsoy, Z. (2006). "Ekonomik Kalkınma ve İşbirliği Örgütü'ne Üye Ülkelerin 2006 Yılı İnsani Gelişmişlik Düzeylerinin Analizi”. 2 (2), 1-18.

Kosmidou, K., Doumpos, M., Zopounidis, C. (2008). Country Risk Evaluation: Springer. 
Lind, N. (2010). “A Calibrated Index of Human Development”. Social Indicators Research, 98 (2), 301-319. doi: 10.1007/s11205-009-9543-5

Manshadi, E. D., Mehregan, M. R., Safari, H. (2015). "Supplier Classification Using UTADIS Method Based on Performance Criteria". International Journal of Academic Research in Business and Social Sciences, 5 (2), 3145. doi: 10.6007/IJARBSS/v5-i2/1457

Nartgün, Ş. S., Kösterelioğlu, M. A., Sipahioğlu, M. (2013). "İnsani Gelişim İndeksi Göstergeleri Açısından AB Üyesi ve AB Üyeliğine Aday Ülkelerin Karşılaştırılması". Trakya Üniversitesi Eğitim Fakültesi Dergisi, 3 (1), 8089.

Nguefack-Tsague, G., Klasen, S., Zucchini, W. (2011). "On Weighting the Components of the Human Development Index: A Statistical Justification”. Journal of Human development and Capabilities, 12 (2), 183-202. doi: 10.1080/19452829.2011.571077

Ogwang, T. (1994). "The Choice of Principle Variables for Computing the Human Development Index". World development, 22 (12), 2011-2014. doi: 10.1016/0305-750X(94)90189-9

Radovanović, B. (2011). "Human Development Index As a Measure of Human Development". Filozofija $i$ drustvo, 22 (3), 193-208. doi: 10.2298/FID1103193R

Ranis, G., Stewart, F. (2000). "Strategies for Success in Human Development". Journal of human development, 1 (1), 49-69. doi: $10.1080 / 14649880050008764$

Safari, H., Ebrahimi, E. (2014). "Using Modified Similarity Multiple Criteria Decision Making Technique to Rank Countries in terms of Human Development Index". Journal of Industrial Engineering and Management, 7 (1), 254-275. doi: 10.3926/jiem.837

Siskos, Y., Yannacopoulos, D. (1985). "UTASTAR: An Ordinal Regression Method For Building Additive Value Functions". Investigação Operacional, 5 (1), 39-53.

Spathis, C., Doumpos, M., Zopounidis, C. (2003). "Using Client Performance Measures to Identify Pre-Engagement Factors Associated with Qualified Audit Reports in Greece". The International Journal of Accounting, 38 (3), 267-284. doi: 10.1016/S0020-7063(03)00047-5

Şahin, G., Gökdemir, L. (2016). “İnsani Gelişme Endeksi Bileşenlerinin Türkiye Ölçeğinde ARDL Sınır Testi İle Sınanması". Gazi İktisat ve Isşletme Dergisi, 2 (1), 1-24.

Tofallis, C. (2013). "An Automatic-Democratic Approach to Weight Setting for the New Human Development Index". Journal of Population Economics, 26 (4), 1325-1345. doi: 10.1007/s00148-012-0432-x

Tunca, M. Z., Ömürbek, N., Cömert, H. G., Aksoy, E. (2016). “OPEC Ülkelerinin Performanslarının Çok Kriterli Karar Verme Yöntemlerinden ENTROPI 
Ülkelerin İnsani Geliş̧mişlik Sinıflamalarının UTADIS Yaklaşımı Aracıllğıyla Yeniden Hesaplanmasl ve Değerlendirilmesi

ve MAUT ile Değerlendirilmesi”. Süleyman Demirel Üniversitesi Vizyoner Dergisi, 7 (14), 1-12.

Ulucan, A., Atıcı, K. B. (2009). "UTADIS Çok Kriterli Sınıflandırma Metodolojisi ve Türkiye Enerji Sektörü Uygulaması". Hacettepe Üniversitesi Iktisadi ve İdari Bilimler Fakültesi Dergisi 27 (2), 141-159.

UNDP. (1990). Human Development Report. New York: United Nations Development Programme.

UNDP. (2010). Human Development Report. New York: United Nations Development Programme.

Voulgaris, F., Doumpos, M., Zopounidis, C. (2000). "On the Evaluation of Greek Industrial Sme's Performance via Multicriteria Analysis of Financial Ratios". Small business economics, 15 (2), 127-136. doi: 10.1023/A:1008159408904

Zhou, P., Ang, B., Poh, K. (2006). "Decision Analysis in Energy and Environmental Modeling: An Update". Energy, 31 (14), 2604-2622. doi: 10.1016/j.energy.2005.10.023

Zopounidis, C., Doumpos, M. (1997). "A Multicriteria Decision Aid Methodology for the Assessment of Country Risk". Investigaciones Europeas de Dirección y Economía de la Empresa, 3 (3), 13-33.

Zopounidis, C., Doumpos, M. (1998). "Developing a multicriteria decision support system for financial classification problems: the finclas system". Optimization Methods and Software, 8 (3-4), 277-304.

Zopounidis, C., Doumpos, M. (1999a). "Business Failure Prediction Using the Utadis Multicriteria Analysis Method". Journal of the Operational Research Society, 50 (11), 1138-1148.

Zopounidis, C., Doumpos, M. (1999b). "A Multicriteria Decision Aid Methodology for Sorting Decision Problems: The Case of Financial Distress". Computational Economics, 14 (3), 197-218.

Zopounidis, C., Doumpos, M. (2000). "PREFDIS: A Multicriteria Decision Support System for Sorting Decision Problems". Computers \& Operations Research, 27 (7-8), 779-797. 